\title{
Aluminum's Involvement in the Progression of Alzheimer's Disease
}

\author{
J.R. Walton* \\ Faculty of Medicine, University of New South Wales, St George Hospital Campus, Sydney NSW, Australia
}

Accepted 10 January 2013

\begin{abstract}
The neuroanatomic specificity with which Alzheimer's disease (AD) progresses could provide clues to AD etiopathology. Magnetic resonance imaging studies of AD clinical progression have confirmed general conclusions from earlier studies of AD neuropathological progression wherein neurofibrillary tangle pathology was observed to spread along a well-defined sequence of corticocortical and corticosubcortical connections, preferentially affecting certain cell types, while sparing others. Identical and non-identical twin studies have consistently shown AD has mixed (environmental and genetic) etiopathogenesis. The decades-long prodromal phase over which AD develops suggests slow but progressive accumulation of a toxic or infective agent over time. Major environmental candidates are reviewed to assess which best fits the profile of an agent that slowly accrues in susceptible cell types of $\mathrm{AD}$-vulnerable brain regions to toxic levels by old age, giving rise to AD neuropathology without rapid neuronal lysis. Chronic aluminum neurotoxicity best matches this profile. Many humans routinely ingest aluminum salts as additives contained in processed foods and alum-treated drinking water. The physical properties of aluminum and ferric iron ions are similar, allowing aluminum to use mechanisms evolved for iron to enter vulnerable neurons involved in $\mathrm{AD}$ progression, accumulate in those neurons, and cause neurofibrillary damage. The genetic component of AD etiopathogenesis apparently involves a susceptibility gene, yet to be identified, that increases aluminum absorption because AD and Down syndrome patients have higher than normal plasma, and brain, aluminum levels. This review describes evidence for aluminum involvement in $\mathrm{AD}$ neuropathology and the clinical progression of sporadic AD.
\end{abstract}

Keywords: Aluminum compounds, Alzheimer's disease, amyloid- $\beta$ protein precursor, animal, causality, disease models, intestinal absorption, neurofibrillary tangles, neurotoxicity syndromes, translational medical research

\section{INTRODUCTION}

One of the most important and challenging problems in contemporary clinical neuroscience is to explain the neuroanatomic specificity of neurodegeneration that occurs in Alzheimer's disease (AD) [1]. That is, to understand why certain large neurons, particularly in the superficial entorhinal cortex, are among the earliest and most severely-damaged cell populations to be affected in AD. An understanding of this selective damage may provide important clues for unraveling AD causality [2].

\footnotetext{
${ }^{*}$ Correspondence to: Dr. J.R. Walton, E-mail: j.walton@unsw. edu.au
}

Epidemiological studies for AD, based on identical and non-identical twin pairs, have consistently shown that AD causality has significant environmental and genetic components. If one member of an identical twin pair develops $\mathrm{AD}$ while the other remains $\mathrm{AD}$-free, the discordance is attributable to an environmental component of AD causality. If identical twins show a higher rate of concordance for $\mathrm{AD}$ than non-identical twins, this provides evidence for a genetic component of $\mathrm{AD}$ causality.

A nationwide Finnish twin cohort study [3] showed more than two-thirds $(68.7 \%)$ of identical twin pairs were discordant for $\mathrm{AD}$, indicating a significant environmental component for AD causality. The same study showed a probandwise concordance rate for $\mathrm{AD}$ 
of $31.3 \%$ in identical twin pairs compared to $9.3 \%$ in non-identical twin pairs, also indicating genetic involvement. Twin-based studies have consistently shown that AD has mixed causality with significant environmental and genetic components [3-5].

Many AD researchers have focused on the genetic component of $\mathrm{AD}$ which is currently believed to involve aberrant metabolism of the amyloid- $\beta$ protein precursor (A $\beta P P)$ and its amyloid- $\beta(A \beta)$ peptide cleavage product. Attention has more recently been directed toward the environmental component of AD. Conventional viruses, prions, and metal neurotoxicants, in particular soluble forms of lead, mercury, and aluminum, have all been proposed for this role. We will consider how well these environmental candidates fit the profile as the environmental component of $\mathrm{AD}$ etiopathogenesis and attempt to understand how that component relates to AD progression.

The present review article has five parts, describing: (1) the anatomical sequencing of interconnected brain regions involved in clinical and neuropathological AD progression; (2) cell and tissue features proposed to enhance the propensity of certain cell types in AD-vulnerable brain regions for neurofibrillary tangle (NFT) formation; (3) a comparison of the major candidates for the environmental component of $\mathrm{AD}$; (4) evidence that the environmental component participates in AD neuropathology; and (5) how the environmental component may interact with cell and tissue features to increase neuronal propensity for NFT formation and its role in $\mathrm{AD}$ progression.

\section{LONGITUDINAL STUDIES OF AD CLINICAL PROGRESSION}

Magnetic resonance imaging (MRI) allows specific brain regions to be mapped in living patients. Brain mapping software, in particular voxel (3D pixel) based morphometry (VBM) [6], can effectively combine multiple MRI scans from a single individual, taken on several occasions over a period of time, to detect rates of atrophy in particular regions of the individual's brain. Alternatively, MRI/VBM can combine brain scans from a population of patients at particular stages of a disease to determine average gray matter volumes at those stages. For $\mathrm{AD}$, cognitive testing of the same subjects is generally carried out close in time to their MRI scans.

Three examples are described here of longitudinal MRI/VBM studies carried out at different stages of AD. The first of these studies takes place in the prodromal phase of $\mathrm{AD}$, comparing brain scans of apparently normal individuals with a family history of $\mathrm{AD}$, which confers an increased risk for this condition, and apparently normal individuals without a family history for $\mathrm{AD}$ [7]. The second study takes place near the end of the prodromal period and compares MRI scans of subjects with (amnestic) mild cognitive impairment (aMCI) before and after they convert to overt $\mathrm{AD}$, with scans performed over the same time period from healthy controls [8]. The third study compares two brain scans, separated by at least one year, from groups of patients diagnosed with probable $\mathrm{AD}$, and age-matched non-demented controls, to demonstrate the gray matter atrophy that occurs over time in specific regions of AD-affected brains [9].

\section{Family history and increased risk of $A D$}

An MRI/VBM study aimed to measure atrophic change in gray matter of cognitively-normal individuals with increased risk for AD due to family history (FH+) [7]. The study included 11 subjects with a maternal history of $\mathrm{AD}$ (FHm), 10 with a paternal history of $\mathrm{AD}(\mathrm{FHp})$, and 32 without any parental history of AD (FH-). Offspring with a family history of AD, particularly from the maternal side, have been shown to have a 4- to 10-fold increased risk for late-onset AD compared to those without a family history of $\mathrm{AD}$ [10].

The prospective subjects, recruited from a referralbased memory clinic, were given a standard diagnostic evaluation. A neurologist used the Clinical Dementia Rating (CDR) scale and the Mini-Mental State Examination (MMSE) to assess the subjects for dementia. Subjects were aged 63-83 years at baseline and had at least 12 years of education. Controls without a family history for AD had a CDR score of zero and a MMSE score of 28 or higher. The subjects were given medical, neuropsychological, and MRI assessments at baseline and at the 2-year follow-up. Gray matter, white matter, and cerebrospinal fluid (CSF) volumes were measured on both occasions and VBM was used to superimpose the MRI scans in order to assess them for change.

Baseline MRI data already revealed significantly greater loss of gray matter and CSF expansion in $\mathrm{FH}+$ subjects than in FH- subjects [7]. The FH+ subjects had significantly more gray matter atrophy than $\mathrm{FH}-$ subjects in the parahippocampus (including the entorhinal cortex), hippocampus, anterior cingulate, medial frontal cortex, and precuneus $(p<0.001)$. When the family history group was split into FHm and FHp sub-groups, only the maternal group showed an association with increased whole brain atrophy. Those in 
the FHm group with an APOE4 allele exhibited significantly more atrophy in the frontal cortex [7].

At the 2-year follow-up visit, further atrophy was observed in the left precuneus and the left parahippocampal gyrus. Atrophy had also increased in the right hippocampus, right precuneus, bilateral middle temporal gyrus, anterior cingulate, and posterior cingulate of those with a positive family history for $\mathrm{AD}$ compared to those without the family history [7].

\section{Conversion from aMCI to $A D$}

The second MRI/VBM study analyzed gray matter loss that occurs in specific brain regions during conversion from aMCI to AD [8]. The study was preceded by data collection from 61 subjects with aMCI who presented for MRI scans on three occasions over a period of time lasting approximately three years. Criteria for aMCI were: memory complaint, impaired memory for their age, almost normal cognitive function, fairly normal activities of daily living, and absence of dementia.

An inclusion criterion for the MRI/VBM analysis was that the patients with aMCI converted to $\mathrm{AD}$ around the three-year timeframe. Hence, the study included 33 subjects with aMCI, who all converted to $\mathrm{AD}$ at a similar rate and had three MRI scans performed during the course of conversion, which occurred over a median interval of three years. The 33 aMCI subjects were compared with 33 healthy controls [8].

The first of three scans was performed approximately 3 years prior to the diagnosis of $\mathrm{AD}$. The second was about one year before $\mathrm{AD}$ diagnosis and the third scan was done at the time of $\mathrm{AD}$ diagnosis. At each time point, all 33 scans for each group were combined with VBM software and templates to determine average gray matter volumes for the aMCI/AD group and the control group.

At the time of the first scan, the averaged gray matter loss in the aMCI cohort was primarily confined to the anterior medial and inferior temporal lobes (bilateral entorhinal cortex, anterior hippocampus, and left amygdala) with some involvement of the fusiform gyrus. The posterior hippocampus was relatively unaffected. Gray matter loss was bilateral, affecting the left hemisphere slightly more than the right hemisphere [8].

At the time of the second scan, the averaged gray matter atrophy in the aMCI group was greater in the medial temporal lobes, inferior temporal lobes, and posterior regions of the temporal lobes, now including the entire hippocampus. Parietal lobes also showed atrophy whereas the frontal lobes were relatively spared [8]. These results show that significant gray matter atrophy occurs before AD is diagnosable.

The 33 aMCI subjects were ultimately diagnosed with $\mathrm{AD}$ at the time of their third scan. Gray matter atrophy in the converted AD group's brains was more extensive throughout the medial temporal lobes and the temporoparietal association neocortices than in the scan taken one year earlier. By this time, gray matter of the frontal lobes showed substantial atrophy for the first time, particularly in anterior frontal lobes and superior frontal gyri. Some gray matter loss was also evident in the midbrain [8]. Other authors confirm that subjects who convert from aMCI to AD have significantly less hippocampal and amygdala gray matter volume and less temporal and parietal lobe cortical thickness than non-converters [11].

Cognitive test scores for the aMCI/AD group also changed over the period during which the three scans were obtained: MMSE scores fell from 27 to 25 to 24 , decreasing 0.9 points per year; CDR scores rose from 1.0 to 2.0 and 3.5 , increasing 0.7 points per year; and Dementia Rating Scale scores decreased from 132 to 125 to 120 or 3 points per year over the span of this period [9]. Other investigators have reported that atrophy of the anterior hippocampus coincides in subjects with a CDR of 0.5 whereas atrophy of the posterior hippocampus is only seen in subjects with a CDR of 2 or 3 [12].

\section{Maps of gray matter atrophy in AD brains}

The third example involves MRI/VBM mapping of the spreading loss of gray matter, imaged on two occasions separated by approximately 1.5 years, averaged from 12 patients diagnosed with probable AD compared to 14 healthy elderly controls [9]. Novel brain mapping methods combined the corresponding cortical regions of all subjects to create average maps that could be visualized in high resolution.

The resulting maps differentiated AD from normal aging (controls) and were able to distinguish different phases of AD. The temporal sequence of deficits that occurs as AD spreads across the cortex was visualized and related to cognitive decline with MMSE scores. The serial MRI images of AD brains indicated gray matter loss had spread from limbic and temporal cortices into frontal and occipital brain regions while sparing sensorimotor cortices. Some local rates of gray matter loss were more than $5 \%$ per year in 
$\mathrm{AD}$ as opposed to $0.9 \%$ per year in controls. The left hemisphere was affected significantly earlier than the right hemisphere. Frontal regions were spared early in the disease but eventually showed more than $15 \%$ loss [9].

\section{Relationship between $A D$ clinical progression and neuropathological progression}

Results from MRI/VBM studies provide quantitative, dynamic visualization of cortical atrophy in living subjects with aMCI and AD and have the advantage that they can be supplemented by cognitive testing. The MRI/VBM studies confirm that gray matter atrophy occurs in a well-defined sequence with $\mathrm{AD}$ progression in a manner that is fundamentally consistent with the temporal sequence previously predicted by studies that relied on postmortem specimens of neuropathological deterioration in $\mathrm{AD}$-affected brain regions. Both approaches have been valuable for analyzing AD progression from one region to another in the aging brain.

\section{SEQUENCING THE BRAIN REGIONS INVOLVED IN AD NEUROPATHOLOGICAL PROGRESSION}

Several neuropathological studies, briefly presented here, have identified brain regions specifically involved in $\mathrm{AD}$ and attempted to determine either the order in which they are affected in $\mathrm{AD}$ progression or the extent of severity to which they are affected [2, 13-17]. Two others examined how many $A \beta$ deposits and NFTs form in brains of older non-demented subjects, relative to their ages $[18,19]$. Another identified brainstem regions also involved in AD [20].

These studies originally analyzed the numbers and distributions of both NFTs and neuritic plaques (NPs) in order to determine which AD hallmark is more suited as a biomarker of brain regions involved in AD progression. All studies ultimately used NFT numbers for evaluating the timing and/or severity of $\mathrm{AD}$-affected brain regions. Reasons for this choice are that NFTs develop within cells located in specific laminae within well-defined brain regions [13]. The characteristic distribution pattern of NFTs permits the differentiation of stages in AD progression. In contrast, NPs have a patchy distribution pattern within discrete architectonic units, significant variation from one brain to another, and multimodal formation [13]. Also, unlike NFTs, $A \beta$ correlates poorly with rates of brain atrophy [21].

\section{Braak staging of AD neuropathological progression}

In 1991, Braak and Braak published a study in which they examined 83 human brains with varying degrees of AD involvement, including 21 from elderly demented humans whose brain tissue had sufficient densities of NFTs to confirm their clinical diagnosis of AD [13]. The study concluded that NFT pathology follows a predictable pattern that allows $\mathrm{AD}$-affected brains to be categorized into six stages: Stages I-II or transentorhinal cortex stages are pre-clinical. (The transentorhinal cortex is in the perirhinal cortex where it interfaces with the entorhinal cortex.) [1]; Stages III-IV or limbic stages are characterized clinically by incipient $\mathrm{AD}$; and Stages V-VI or neocortical stages are characterized by overt AD (Table 1). Studies of severe $\mathrm{AD}$ are complicated by wide-scale neuron loss and increasing neuropathology in glia and nonpyramidal cells [22]. The Braak hierarchical model of AD neuropathology has been critically tested and validated by Gertz et al. [23].

\section{Cell-cell connectivity and AD neuropathological progression}

Pearson et al. showed that cell-cell connectivity plays an essential role in AD progression [14]. More specifically, they observed that $\mathrm{AD}$ neurodegeneration commences in olfactory structures located in the medial temporal lobe and then spreads widely via anatomical connections to more distant cortical regions (Table 1).

Deafferentation of corticocortical fibers in one brain region may result in NFT damage within the region to which those corticocortical fibers normally project [14]. NFTs appear to develop in conjunction with denervation of short feed-forward and/or feed-back corticocortical fibers as well as the ascending or descending paths. The number of pyramidal cells with NFTs in layer $\mathrm{V}$ of the middle temporal neocortex is in a $2: 1$ ratio with NFT-containing pyramidal cells in layer III. Moreover, the NFTs of layers III and V are arranged in clusters that are in register with each other. There is close correspondence between the distribution of NFTs in the neocortex and damage in anatomically connected regions [14].

\section{NFT counts indicate AD-affected brain regions}

The cells of origin for the perforant pathway, located in layers II and III of the superficial entorhinal cortex, 
Table 1

Sequences of NFT-affected brain regions, with regard to timing or severity, in neuropathological AD progression

\begin{tabular}{|c|c|c|c|c|}
\hline Braak stages & Braak and Braak, 1991 [13] & Arnold et al., 1990 [15] & Kovács et al., 2001 [17] & Pearson, 1996 [14] \\
\hline Stage I & transentorhinal cortex & entorhinal cortex & olfactory bulb & piriform cortex \\
\hline Stage II & entorhinal cortex, CA1 & subiculum/CA1 complex & $\begin{array}{l}\text { anterior olfactory } \\
\text { nucleus }\end{array}$ & entorhinal cortex \\
\hline \multirow[t]{5}{*}{ Stage III } & amygdala, basolateral nucleus & temporal pole cortex & entorhinal cortex & amygdala \\
\hline & anterodorsal thalamus & perirhinal cortex & periamygdaloid cortex & agranular insula \\
\hline & reunions nucleus, hypothalamic & amygdala, access basal nucleus & CA1 field & orbitofrontal area \\
\hline & tuberomamillary nucleus & post parahippocampal cortex & anterior amygdala & CA1/subicular complex \\
\hline & basal magnocellular complex & nucleus basalis of Meynert & gyrus rectus & perirhinal cortex \\
\hline \multirow[t]{3}{*}{ Stage IV } & accumbens nucleus, putamen & anterior insula & lateral orbitofrontal cx & $\begin{array}{l}\text { assoc areas anterior } \\
\text { temporal gyri }\end{array}$ \\
\hline & corticomedial amygdala & mid and inferior temporal cortex & occipital cortex & assoc areas cingulate cortex \\
\hline & basal claustrum, striatum & non-primary association cortex & cingulate cortex & temporal pole cortex \\
\hline \multirow[t]{7}{*}{ Stage V } & $\begin{array}{l}\text { parasubiculum, transsubiculum } \\
\text { subiculum, CA4, putamen } \\
\text { all neocortex association areas }\end{array}$ & $\begin{array}{l}\text { superior temporal cortex } \\
\text { orbitofrontal } \mathrm{cx} \\
\text { fusiform cortex }\end{array}$ & & $\begin{array}{l}\text { assoc area inferior parietal } \\
\text { inferior parietal } \\
\text { dorsolateral prefrontal assoc } \\
\text { areas }\end{array}$ \\
\hline & anterobasal insula, uncus & primary sensory assoc cortex & & post assoc areas temp lobe \\
\hline & orbitofrontal cortex & retrosplenial cortex & & $\begin{array}{l}\text { post assoc areas sup parietal } \\
\text { lobe }\end{array}$ \\
\hline & substantia nigra pars complex & $\begin{array}{l}\text { ventral ant \& post cingulate } \\
\text { cortices }\end{array}$ & & frontal pole \\
\hline & thalamus, anteroventral nucleus & dorsal cingulate cortex & & posterior prefrontal cortex \\
\hline & orbitofrontal cortex & dorsal prefrontal cortex & & \\
\hline & $\begin{array}{l}\text { hypothalamic lateral tuberal } \\
\text { nucleus }\end{array}$ & agranular cortex & & \\
\hline Stage VI & $\begin{array}{l}\text { fascia dentata } \\
\text { extrapyramidal system }\end{array}$ & primary sensory areas & & \\
\hline
\end{tabular}

collect incoming information from sensory association cortices, which is relayed to the dentate gyrus and CA1/subiculum zone of the hippocampal formation. These cells contain more NFTs than cells in any other of the 30 cortical regions of the AD brain examined in a study by Arnold et al. [15] (Table 1). They are selectively vulnerable during aging and MCI as well as $\mathrm{AD}$, suggesting they become damaged at a very early stage [24]. Other large pyramidal cells, in layer IV of the entorhinal cortex, are also heavily invested with NFTs, but at a later stage than those in the superficial entorhinal cortex. By endstage AD, all cell layers of the entorhinal cortex are devastated [1].

The hippocampal CA1/subiculum zone is also severely affected by NFT formation whereas other areas of the hippocampal formation are largely spared. The entorhinal cortex/hippocampus/amygdala regions are the most severely affected in $\mathrm{AD}$, on the basis of NFT numbers, whereas the motor and primary sensory cortices are the least affected [15]. Many more NFTs are located in limbic and temporal lobes than in the parietal, frontal, and occipital lobes. Neurons in layers II and IV of the entorhinal cortex have substantial afferent and efferent interconnections with temporal and posterior parietal higher order neocortical association areas [25], the most NFT-damaged regions in the
AD neocortex [26]. The laminar distribution of NFTs in all neocortical association areas favors layers III and $\mathrm{V}$ with relatively few NFTs appearing in cortical layers II, IV, and VI [14, 15].

NFTs and NPs have different distribution patterns, with NFTs being more selectively distributed than NPs [15]. Most NPs are found in neocortical layers II, III, IV, and V [14]. The selective involvement of NFT damage in neurons of layers III and V of the association cortices is expected to disrupt corticocortical and corticosubcortical connections [14, 15, 27].

\section{Olfactory deterioration in AD neuropathological progression}

Kovács and colleagues [16, 17] counted NFTs in olfactory structures to link the olfactory bulb and related olfactory regions to the Braak hierarchical model for AD staging [16], and to explain the wellknown observation that olfaction is impaired at an early stage of AD (Table 1). They concluded that: (1) the olfactory bulb is one of the first structures to develop NFTs; (2) this may occur prior to NFT damage in the entorhinal cortex; (3) NFTs are observed in olfactory bulbs at Braak stages 0 or I; and (4) impaired olfaction in early stages of AD is attributable to early NFT dam- 
age in the olfactory bulb and anterior olfactory nucleus $[16,17]$.

\section{NFTs in subcortical nuclei}

Pyramidal neurons of neocortical layer $\mathrm{V}$ project to the striatum, the nucleus basalis of Meynert, and the brainstem. The nucleus basalis is virtually devoid of tangles in brains from non-demented individuals under age 75 years and shows only a few NFTs in brains of older controls [19]. The nucleus basalis of Meynert is highly variable between AD cases, some being barely affected and others severely affected by NFTs [15].

Certain brainstem nuclei are selectively vulnerable to $\mathrm{AD}[20]$ and their deterioration may give rise to additional features of $\mathrm{AD}$. The dorsal raphe complex is severely invested by NFTs in most AD cases. The dorsal raphe complex consists mainly of serotonergic neurons and accounts for a substantial proportion of the major ascending serotonergic projections to the forebrain. Dorsal raphe pathology could account for the significant decrease in serotonergic innervation and serotonin decrease in the CSF of AD patients [20].

The locus coeruleus is also severely affected in AD. Damage occurs in the locus coeruleus at a very early stage of $\mathrm{AD}$, possibly preceding damage in the transentorhinal cortex [28], a finding that should be examined with MRI/VBM. This nucleus has major noradrenergic projections to basal forebrain nuclei and several cortical regions. Pathology in the locus coeruleus may underlie disorders of selective attention and neural control of sleep and wakefulness [20].

\section{NFTs and $A \beta$ deposits: Which occurs first in $A D$ ?}

A search for NFTs and $A \beta$ in limbic regions from non-demented subjects under age 65 revealed that 22 (58\%) of the 38 brains showed AD change in the form of NFTs only [18]. Three (8\%) seemed to have only A $\beta$ deposits and $13(34 \%)$ had both NFTs and A $\beta$ deposits. Almost all $A \beta$ deposits observed in brains of these nondemented middle-aged humans were primitive. Classic plaques with cores were seldom observed [18]. These findings [18] are very similar to findings from a study by Kovács et al. [16] who reported that all $15 \mathrm{AD}$ cases and $13(87 \%)$ of the 15 aged controls they examined exhibited NFTs in the olfactory bulb whereas only 5 (33\%) had $\mathrm{A} \beta$ deposits and these were diffuse. Compact and neuritic $A \beta$ plaques were not seen [16]. Thus, NFTs appear earlier than $A \beta$ deposits in olfactory and limbic regions, even in controls $[16,18]$.
The view expressed by Kovács et al. [16] that the olfactory region is affected by AD neuropathology prior to the entorhinal cortex is countered by the argument that $\mathrm{AD}$ affects the entorhinal cortex before the olfactory mucosa or olfactory bulb [18]. According to Ulrich, NFTs are sometimes seen in the entorhinal cortex and/or hippocampus while absent from the olfactory bulb. However, it is never the case that NFTs are present in the olfactory bulb while absent from the entorhinal cortex and/or hippocampus [18].

The hippocampus, entorhinal cortex, and nucleus basalis of Meynert contain fewer NPs per field than any other region [15]. The entorhinal cortex has one of the lowest NP densities, and most NPs in this region are located in layer III. By the time AD is evident, entorhinal cortical cells of origin for the perforant pathway are heavily invested with NFTs with many in the form of extracellular "ghosts" [25]. Damage to the perforant pathway involves deterioration of its glutamatergic terminals that normally innervate the hippocampal formation. This ultimately results in disconnection of the hippocampal formation from the entorhinal cortex and, hence, the neocortex [29]. A layer of NPs forms in the center of the dentate gyrus molecular layer, precisely where the terminals of the perforant pathway were previously located $[29,30]$.

The amyloid cascade hypothesis assumes that $\mathrm{A} \beta$ deposits precede NFTs and cause their formation [31]. $\mathrm{A} \beta$ deposition is much more prominent in the neocortex of controls and AD cases than in limbic regions [14, $16]$. The average $A \beta$ plaque density in the temporal, insular, and orbital cortices is three-fold greater than in the hippocampal CA1 field. Also, $A \beta$ plaques were observed to have formed in the temporal neocortex prior to neocortical NFTs [19].

However, these findings are insufficient to support the concept that $A \beta$ deposition precedes and causes NFTs. Studies of AD progression have shown that the limbic regions which, on average, exhibit AD neuropathology 25 years earlier than neocortical regions [32] show NFTs in most brains earlier than $A \beta$ deposits $[16,18]$. The occurrence of $A \beta$ plaques preceding NFTs in the neocortex raises the possibility that neocortical $A \beta$ plaques could form in response to NFT damage from layer IV neurons of the entorhinal cortex and/or from AD-affected hippocampal CA1 neurons that normally project to the neocortex, rather than from neocortical sources. For example, the hippocampus has stronger feed-forward output to the medial temporal gyrus than feedback from the medial temporal gyrus [33]. Thus, NFT-induced damage in the hippocampus could result in $A \beta$ plaques in the medial temporal 
gyrus. Tau pathology in limbic regions precedes $A \beta$ pathology by at least 27 years [22, 34]. Immunostained tau is visible in brain tissue of many children and young adults despite the absence of evidence for immunoreactive $A \beta[22]$.

\section{Connectivity and disconnectivity in $A D$}

AD-affected brain regions are interconnected with each other [14], causing some investigators to describe $\mathrm{AD}$ as a connection syndrome and others as a disconnection syndrome. Olfactory pathway-innervated brain regions include certain neocortical regions. Subcortical neurons that directly project to these neocortical regions are also selectively vulnerable in $\mathrm{AD}$. It has been postulated that $\mathrm{AD}$ neuropathology results from an agent that crosses synapses, spreading in an anterograde direction between connected corticocortical and corticosubcortical cells of AD-vulnerable brain regions [26]. Spread of an agent from one brain region to another may provoke cell changes that lead to the formation of NFTs in the soma and dendrites of target neurons. For example, hyperphosphorylated tau has been proposed to spread between interconnected brain regions in $\mathrm{AD}$ [35-37]. An alternate explanation for the apparent spread of hyperphosphorylated tau in interconnected brain regions is discussed below in the section "Aluminum and AD Progression".

AD damage may also spread between specific brain regions in a retrograde direction since synaptic terminals have active incorporation of plasma membrane, indiscriminately taking in neuropil substances that can be transported back to the cell soma [38]. This mechanism involves plasma membrane invagination with vesicles budding into the cytoplasm [39]. Small membrane-bound vesicles are transported retrogradely by kinesin along microtubules at rates similar to fast anterograde transport [40]. AD progression could also spread simultaneously in both anterograde and retrograde directions via different sets of fibers [14].

Paradoxically, the neuropathology of $\mathrm{AD}$ is also consistent with its being a disconnection syndrome, involving disruption to afferent and efferent connections of NFT-containing corticocortical cells [27]. AD neuropathology probably involves connections at one stage and disconnections at another. For example, cellcell connectivity could allow the propagation of a neurotoxic agent throughout a sequence of specific brain regions, giving rise to NFTs and cytoskeletal damage that eventually disrupt these connections and result in functional loss.

\section{A consensus on AD neuropathological progression}

The Braak hierarchical model for AD progression and other studies described above support the concept that, toward the end of a long prodromal phase, NFT neuropathology is already spreading in a stepwise manner along well-defined corticocortical connections between the entorhinal cortex and other limbic structures. More brain regions become involved as $\mathrm{AD}$ progresses. MRI/VBM studies on brains of living ADaffected humans and postmortem brains of humans who died with AD have confirmed this observation and enabled a consensus view on the general sequence of $\mathrm{AD}$ progression.

The entorhinal cortex and the transentorhinal cortex are damaged earlier in AD than other limbic regions. Damage in the limbic regions is followed by NFT damage in temporoparietal neocortices with association areas affected earlier and to a greater extent than primary sensory areas. The frontal and occipital cortices then show damage while the sensorimotor cortices are largely spared. Some subcortical regions are also involved in $\mathrm{AD}$ but those of the brainstem have been less studied. AD-affected brain regions are all interconnected.

AD preferentially affects certain cell types in ADvulnerable brain regions. Next we consider possible reasons why certain types of neurons are preferentially affected, both earlier and to a more severe extent than other cell types.

\section{CELLULAR AND TISSUE FEATURES THAT INCREASE CELL SUSCEPTIBILITY TO NFT FORMATION}

The large corticortical stellate neurons in layer II and underlying pyramidal cells in the superficial part of layer III of the entorhinal cortex are, as mentioned, the cells of origin for the perforant pathway (Fig. 1) [25]. These particular cells have a high risk for developing NFTs in AD and must have at least one, or more, unique qualities that predispose them to NFT formation.

Several cellular and tissue features have been proposed to account for this phenomenon.

- Firstly, the cell types that develop NFTs are generally complex with a long axon and large surface area [42].

- Secondly, they have high energy demands, high densities of transferrin receptors, and elevated iron uptake $[43,44]$. 


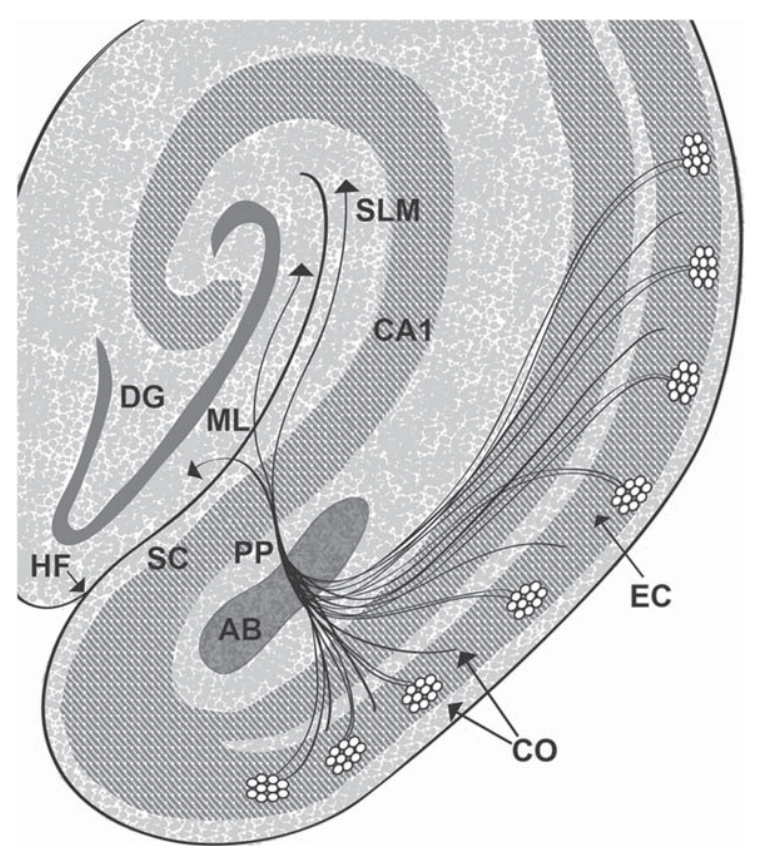

Fig. 1. Entorhinal cortex cells of origin for the perforant pathway. Schematic representation of the perforant pathway. The perforant pathway is similar for humans and rats apart from minor variations. The cells of origin (CO) for the perforant pathway reside in layer II (shown as cell islands) and in the superficial part of layer III of the entorhinal cortex (EC). The cells of origin receive information from many cortical regions. Axons of the cells of origin converge in the angular bundle $(\mathrm{AB})$. The axons leave the angular bundle and diverge into fascicles known as the perforant pathway (PP) because the axons perforate through the gray matter of the subicular cortex (SC) to the hippocampal formation (dentate gyrus and hippocampus proper). A contingent of fascicles enters the stratum lacunosum moleculare (SLM) of the hippocampal CA1/subicular zone (CA1). More fascicles cross the hippocampal fissure (HF) to enter the molecular layer (ML) of the dentate gyrus (DG). Reproduced from [41] (Copyright: JR Walton).

- Thirdly, NFTs form more readily in cells that are poorly myelinated [45].

- Fourthly, a cell may be more susceptible to NFT formation if exceptionally well-vascularized.

\section{Cell size and complexity}

The reasoning behind the proposal that complex cells with a large surface area are most prone to NFT development is that these traits would provide increased exposure to toxic agents in the extracellular milieu [42]. This proposal is probably based on observations that most cells that develop NFTs are large corticocortical and corticosubcortical pyramidal or stellate cells. In contrast, small neurons, such as the spiny stellate cells in entorhinal cortex layer IV and inhibitory interneurons seldom, if ever, contain NFTs [46].

The total dendritic length in layer II neurons of the entorhinal cortex and the hippocampal CA1 zone of non-human primates can both reach $8.0 \mathrm{~mm}$, implying these two cell types have comparable complexity [42]. However, the entorhinal cortex is consistently damaged earlier and more severely by NFT formation than the CA1/subiculum zone despite the comparable complexity of corticocortical cells in both brain regions. This led Stranahan and Mattson [42] to conclude that some other cell feature must also be important.

\section{High energy demands, densities of transferrin (Tf) receptors, and iron uptake}

A second possibility for increased cell vulnerability to AD could come from particularly high energy demands, high densities of Tf receptors, and the large mitochondrial iron requirement necessary to generate sufficient ATP to meet such high metabolic requirements. Cells with these features may be more vulnerable to NFT formation than cells with relatively low metabolic demands.

Plasma iron circulates in the form of transferrinbound iron (Tf-iron). Figure 2 illustrates iron uptake and utilization, storage, and exit from a generic cell [47]. These processes are similar in capillary endothelial cells of the blood-brain barrier. The Tf-iron attaches to $\mathrm{Tf}$ receptors on the luminal surface of the cerebral capillary endothelium, initiating iron transport across the blood-brain barrier [49]. Upon being released to the cytoplasm of endothelial cells, iron excessive to that required by the endothelial cell is transported across its abluminal surface and into the extracellular matrix by ferroportin. Iron also crosses the blood-brain barrier by Tf-independent mechanisms [50, 51]. Iron exiting from the endothelium binds to extracellular Tf generated by oligodendrocytes, astrocytes, and/or the choroid plexus [52]. The Tf-bound iron is then taken up into neurons via $\mathrm{Tf}$ receptors on the neuronal surface [53].

\section{High energy demands}

Multipolar stellate cells and pyramidal cells in islands of the superficial entorhinal cortex are especially vulnerable to NFT formation. These cells of origin for the perforant pathway are grouped into functional modules that have particularly heavy metabolic demands during waking hours and paradoxical (REM) sleep [54]. Cytochrome oxidase staining confirms that these entorhinal cortical cells function as cytochrome 


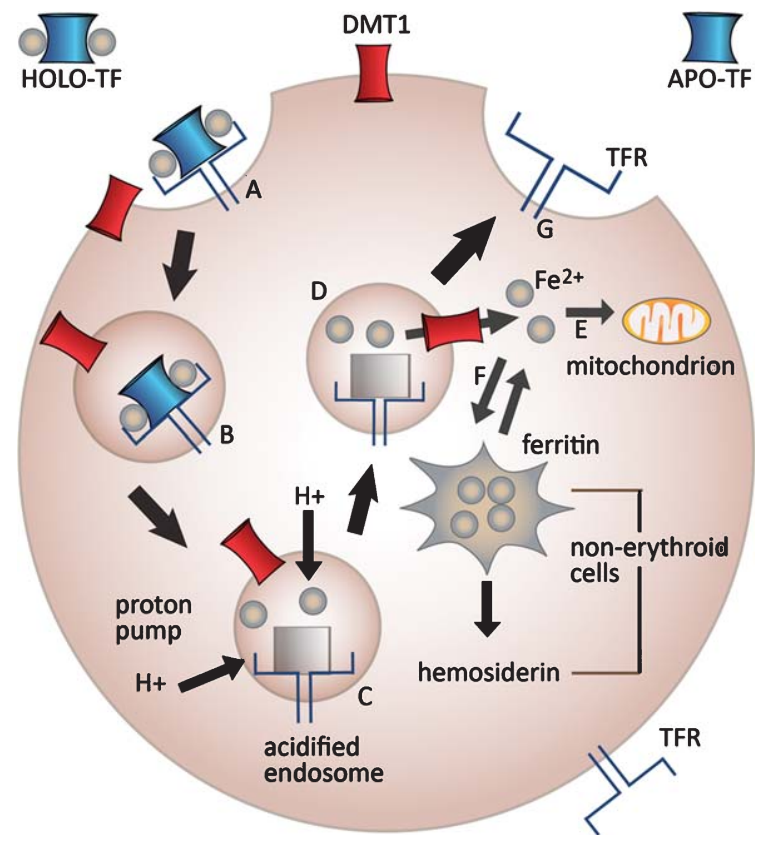

Fig. 2. Generic diagram of iron uptake into cells. A) Tf-iron binds to Tf receptors (TFR) at the cell surface. B) The Tf-iron/TfR complexes are internalized in clathrin-coated vesicles. C) ATP-dependent proton pumps $\left(\mathrm{H}^{+}\right)$acidify the endosome, releasing iron from the Tf/TFR complex. D) Iron exits the endosome via the divalent metal ion transporter DCT1 [48]. E) The free iron $\left(\mathrm{Fe}^{2+}\right)$ is either used by the cell for mitochondrial respiration or incorporated into ironcontaining proteins. F) The remainder of iron is either stored in ferritin deposits or transported out of the cell via ferroportin (not shown). G) Meanwhile, the Tf/TFR complex is returned to the cell membrane where the complex dissociates, releasing Tf for re-use. Reproduced from [47] with permission from John Wiley \& Sons.

oxidase-rich modules [54]. Intrinsic electrical properties of the stellate cells, involving oscillations associated with gamma and theta rhythms [55], are highly correlated in all behavioral states and also contribute toward their necessarily high bioenergetic needs [54]. Cells in the perirhinal cortex (including the transentorhinal cortex) also display oscillations in the theta range [56]. Consequently, corticocortical cells in both the entorhinal and perirhinal regions have high glucose utilization and a very high level of mitochondrial respiration [57].

\section{Transferrin receptor density}

Neurons with large metabolic demands have high densities of $\mathrm{Tf}$ receptors on their surface that allow them to import sufficient iron to meet their high-energy demands [43]. Glial cell membranes also have Tf receptors [58]. Brain regions containing neurons with high densities of $\mathrm{Tf}$ receptors show almost identical distribution to those with neurons that have with high numbers of mitochondrial respiratory chains and high cytochrome oxidase levels [59]. Cytochrome oxidase, the terminal enzyme of the electron transport chain, serves as a marker of metabolic activity in neurons [44].

The entorhinal cortex, hippocampus, amygdala, temporal and parietal cortex, locus coeruleus, and dorsal raphe nucleus all contain relatively high densities of $\mathrm{Tf}$ receptors compared to other brain regions [43, 44, 59-61]. However, high Tf receptor density on its own is insufficient to explain selective neuronal vulnerability to $\mathrm{AD}$ since other cell groups that have high Tf receptor densities, such as the olives and trigeminal nucleus, fail to show evidence of selective neurodegeneration in $\mathrm{AD}$ [60]. This suggests that high Tf receptor density in cells is more relevant to AD vulnerability if those cells are interconnected with cells in other AD-vulnerable brain regions.

\section{Iron regulatory proteins (IRPs)}

Iron is an essential metal in cell metabolism for ATP production, DNA polymerases and repair, synthesis of heme proteins, and catecholamine neurotransmitters. Each mitochondrial respiratory chain requires up to 40 iron atoms [61]. Intracellular iron metabolism is controlled by iron regulatory proteins 1 and 2 (IRP1, IRP2), that act as iron sensors, as described in Fig. 3 $[62,63]$. Normally, when cells are iron-deficient, synthesis of the iron-storage protein ferritin is repressed (Fig. 3A) whereas Tf receptor synthesis and iron uptake resume (Fig. 3B). When the cells have enough iron, ferritin synthesis is activated (Fig. 3C) and Tf receptor synthesis shuts down, reducing iron uptake (Fig. 3D). This process is cyclical in healthy cells, ensuring that cells have sufficient, but not excessive, free iron.

Iron metabolism becomes disregulated in the most vulnerable regions of $\mathrm{AD}$ brains. The disregulation occurs as a result of IRP2 stabilization which in turn maintains Tf receptor mRNA in a stabilized state [65]. IRP2 stabilization makes the cells behave as though they are in a permanent state of iron deficiency. This stabilized state occurs because, for some reason, IRP2 does not degrade as normally happens when iron levels are adequate. Consequently, cells in these vulnerable regions continue to synthesize Tf receptors and import more iron than the cell ferritin deposits can store.

In $\mathrm{AD}$, iron levels become significantly more elevated in the hippocampus, amygdala, temporal cortex, and parietal cortex compared to control brains [66]. This excess iron contributes to increasing oxidative damage in large corticocortical cells of the 


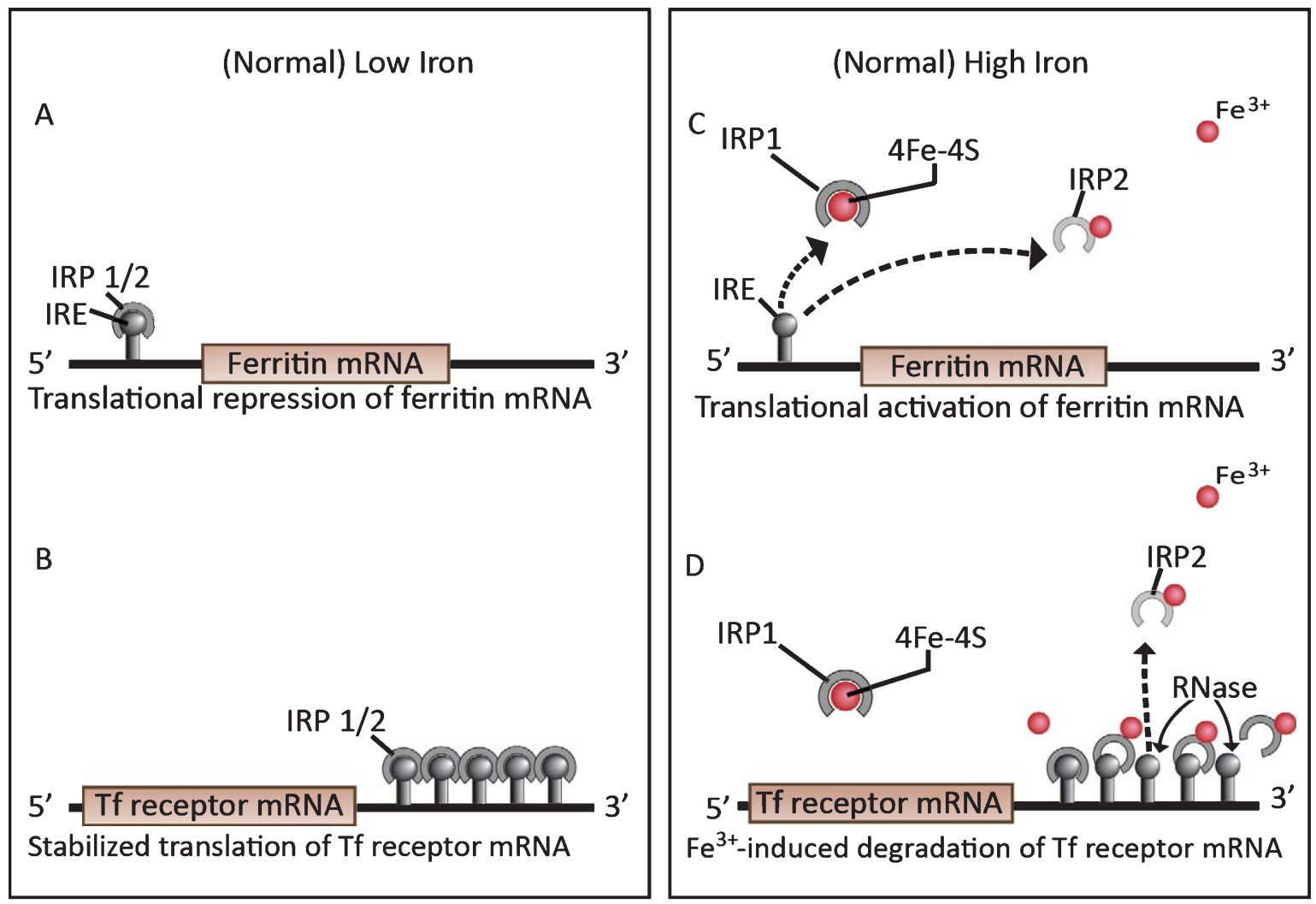

Fig. 3. Iron regulatory proteins (IRP) 1 and 2 under low and high iron conditions in neurons. Ferritin mRNA activity (A\&C) is reciprocal with Tf receptor mRNA activity (B and D, respectively). A) When intracellular iron is deficient, IRPs 1 and 2 bind with high affinity to the iron regulatory element (IRE) in the $5^{\prime}$ UTR of ferritin mRNA, repressing its translation. B) IRP binding to the five IREs in the $3^{\prime}$ UTR of Tf receptor mRNA stabilize its translation by protecting the mRNA from RNase degradation. This allows the continuation of Tf receptor synthesis and iron uptake until the iron supply is again replete. C) The small spheres indicate excess ferric iron ions $\left(\mathrm{Fe}^{3+}\right)$. When the iron supply is replete, $\mathrm{Fe}^{3+}$ binds to a $\mathrm{Fe}^{3+}$-binding site on the IRP2, oxidizes the IRP2 and causes it to lose its affinity for the IRE. IRP detachment from the $5^{\prime}$ end of ferritin mRNA activates ferritin translation. The dotted line indicates a deteriorating IRP2 that has detached from its IRE and signaled for degradation by the ubiquinol-proteosomal pathway (61-63). The higher $\mathrm{Fe}^{3+}$ level changes the conformation of IRP1 from an RNA-binding protein to an inactive form that binds an iron-sulfur cluster (4Fe-4S). D) As in $\mathrm{C}, \mathrm{Fe}^{3+}$ binds to iron-binding sites on the IRP2s, oxidizing them, and causing IRP2 detachment from the IREs and signaling for IRP2 degradation [62-64]. This exposes the Tf receptor mRNA to degradation by intracellular RNases. Consequently, iron uptake ceases. Reproduced from [61] with permission from Elsevier.

AD-vulnerable brain regions. Excess iron imported into these neurons participates in NFT formation by aggregating hyperphosphorylated tau and binding to NFTs [67].

\section{Scanty myelination increases cell susceptibility to NFT formation}

Poorly myelinated cells are highly prone to NFT formation $[68,69]$. Primary sensory areas of the neocortex are very well myelinated but the density of myelination decreases with increasing distance from primary sensory areas [68-70]. Thus, neocortical association areas are less well myelinated, particularly in the higher order association areas. Limbic tissues including the entorhinal cortex, hippocampal formation, and amygdala are in the phylogenetically-oldest allocortex and these are the most poorly myelinated and most NFTprone regions of the AD brain [45].

Increased vulnerability is conferred on the poorly myelinated entorhinal cortical neurons by their huge demands for energy generation. A high degree of axonal myelination on neurons in primary sensory areas increases the velocity of their signal conduction while reducing cellular energy expenditures about 5,000 times [71]. Conversely, poorly myelinated neurons, such as those of the entorhinal cortex, have leaky axons and must generate vastly ( 5,000-fold) more energy to compensate for the significant wastage. Poorly myelinated pyramidal cells are much more 
susceptible to oxidative damage. Consequently, those cells accumulate lipofuscin pigment and exhibit early evidence of cellular aging [45].

Poor myelination in the olfactory limbic system is likely to be one reason why the entorhinal cortex, hippocampus, amygdala, and olfactory bulb are generally more vulnerable to NFT pathology than neocortical regions. However, poor myelination on its own fails to explain why the entorhinal cortex is more vulnerable to NFT formation at an earlier time than other limbic structures.

\section{Redundant vascularization may increase cell susceptibility to NFT formation}

The final feature considered here that may increase a cell's susceptibility to NFTs pertains to vascular redundancy. Neuronal firing increases blood flow by evoking the redistribution of patent capillaries [72]. Hence, neurons with high firing activity increase blood flow. Conversely, neurons damaged and unable to fire have a decreased vascular supply.

Blood flow to a brain region is also dependent on capillary density. This may explain why stellate and pyramidal cells in the superficial entorhinal cortex are selectively more vulnerable to NFT pathology than cells in other limbic regions. The entorhinal cortex of the guinea pig brain is supplied by caudal and rostral posterior arteries, with a very broad overlap between their distal territories, and also by the middle cerebral artery [73]. Such redundancy is potentially protective against hypoxic events. The redundant vascular input to the entorhinal cortex also increases its exposure to blood-borne toxicants and inflammatory factors. In contrast, the ventral part of the hippocampal formation is exclusively supplied by the rostral posterior cerebral artery [73]. This may explain hippocampal susceptibility to transient global ischemia [74].

The human entorhinal cortex receives its vascular input from both the posterior and middle cerebral arteries and has abundant anastomotic links [75]. Satellite arterioles, among the dense reticular matrix of axons that surround islands of multipolar stellate cells and pyramidal cells in layer II, give rise to a dense meshwork of capillaries that invade these islands (Fig. 4) [1].

Capillaries of different brain regions have a relatively uniform density of $\mathrm{Tf}$ receptors on their surface [76]. However, a higher capillary density should provide more endothelial cells and more $\mathrm{Tf}$ receptors that can, in principle, move larger amounts of iron and other blood-borne agents across the blood-brain bar-
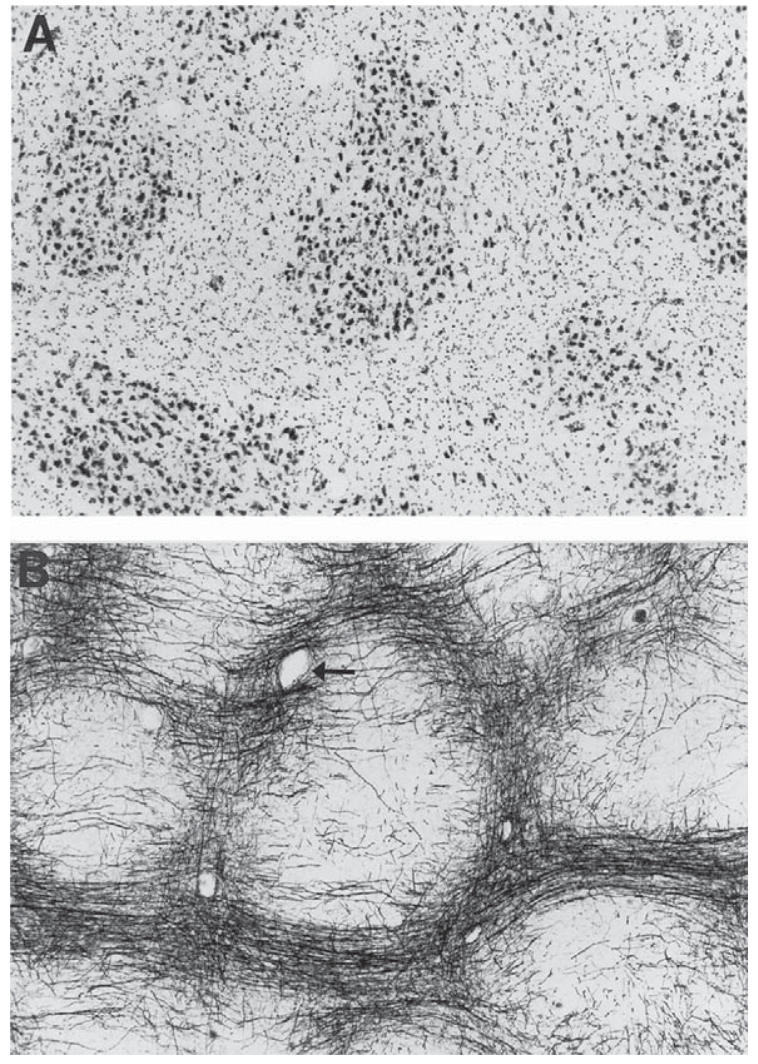

Fig. 4. Vascularization of cell islands in the human entorhinal cortex. A) This tangential section through layer II of the human entorhinal cortex is stained with cresyl violet. Note the islands of large neurons. B) An adjacent section to that shown in A, stained with the Gallyas method, shows the complex axonal matrix that surrounds the cell islands. Note the satellite arterioles (e.g., arrow) among the surrounding axonal fibers. The arterioles that surround the cell islands branch and give rise to a dense capillary meshwork that heavily invests the cell islands. Reproduced from [1] with permission from John Wiley \& Sons.

rier into the extracellular matrix of well-vascularized neurons.

\section{LARGE CELL SIZE, HIGH ENERGY AND IRON DEMANDS, SCANTY MYELINATION, AND REDUNDANT VASCULARIZATION ARE INSUFFICIENT TO CAUSE NFT FORMATION}

Here we focus on the large corticocortical cells of the superficial entorhinal cortex that become profoundly affected at a relatively early stage of AD [77], to assess whether they have any single feature, or combination of the cell and tissue features described above, that might account for their susceptibility for early NFT formation. Stellate and pyramidal cells of 
the superficial entorhinal cortex are poorly myelinated cells, extremely active, and have a high density of $\mathrm{Tf}$ receptors on their surfaces and high iron uptake. The superficial entorhinal cortex has a redundant vascular supply and its cell islands are surrounded by a dense capillary network.

It is likely that each of the proposed features contributes to increased susceptibility for NFT formation in these cells of origin for the perforant pathway. However, these features are also characteristic of their counterpart cells that are functioning well in healthy young and non-demented aged brains. Hence, a trigger that disrupts normal cell metabolism in these ADvulnerable cells is also necessary.

\section{AGENTS PROPOSED AS THE ENVIRONMENTAL COMPONENT OF AD}

The main candidates for the environmental component of $\mathrm{AD}$ are prions (atypical slow viruses), conventional viruses, and metal neurotoxicants. These candidates are reviewed to determine which best fits the profile of an environmental trigger that slowly accumulates in the brain over decades, specifically in affected neurons of $\mathrm{AD}$-vulnerable brain regions, to reach toxic levels in old age and produce AD neuropathology without rapidly lysing the affected neurons.

A microorganism proposed as the environmental cause of AD should fulfill Koch's postulates. These are: (1) the microorganism must be present in every case of the disease under study; (2) the microorganism should be capable of being isolated and grown in pure culture; (3) the microorganism must, when inoculated into susceptible animals, cause the disease under study; (4) The microorganism must be recovered from the inoculated animals and identified.

\section{Prions}

Human prion diseases are infectious, transmissible, and hereditable, between species as well as within species unlike AD. The brain regions that are affected relatively early in prion diseases include the pulvinar, ventrolateral, and mediodorsal thalamic nuclei, the putamen, and caudate nucleus [78]. The hippocampal formation is relatively spared. Damage in these brain regions is inconsistent with $\mathrm{AD}$ progression. Prion protein deposits, vacuoles, and rapid cell death further distinguish prion disease neuropathology from $\mathrm{AD}$ neuropathology [79].

A large study conducted at the National Institutes of Health carried out extensive testing of brain sam- ples from 52 autopsy-confirmed AD patients [80], transplanting them into the brains of 61 non-human primates to learn whether a transmissible agent is involved in AD. Only two animals developed a spongiform encephalopathy. A further 17 cases were tested for more than 50 months without any effect. The investigators re-tested samples from the same brain tissue that had previously produced positive results for encephalopathy. Positive findings were elusive upon re-testing. This led the authors to conclude that an infectious agent is not involved in AD causality [80]. Subsequent testing of 36 additional AD brain samples confirmed these conclusions [81].

These AD results contrast with those from another NIH study of prion disease transmissibility. Transplanted brain samples into non-human primates showed transmission rates of $100 \%$ for eight subjects with iatrogenic Creutzfeldt-Jakob disease, $90 \%$ for 234 patients with sporadic Creutzfeldt-Jakob disease, 68\% for 36 cases with familial Creutzfeldt-Jacob disease, and $95 \%$ for 18 (biopsied) patients with kuru [81]. These samples were injected into $45,1167,197$, and 45 primates, respectively. As for $\mathrm{AD}$, animals that died from any cause were given neuropathological examinations and designated as positive if they showed typical spongiform change in their brain.

\section{Common viruses}

Common viruses have also been considered as possible environmental causes of AD. Herpes simplex virus 1 (HSV1) can persist in a latent form for many years without showing overt disease after primary infection. It can reactivate from the latent state and cause cold sores and mouth, throat, face, and eye problems, despite the presence of circulating antibodies. HSV1 is one of many micro-organisms that stimulate $\mathrm{NF \kappa B}$ [82] which in turn upregulates the gene for A $\beta P P$ [83], and genes for other stress-response proteins, leading to increased $A \beta$ formation in experimental systems [84].

HSV/HSV1 immunoreactivity has been reported in AD and normal brain tissue [85-87] and HSV DNA was detected in 3 of 4 brain smears [88]. However, larger DNA hybridization studies have been unable to confirm the specific presence of HSV DNA in AD brain tissue [89-91]. HSV antibody titers of AD patients are similar to those of controls [92-94].

HSV1 is also neurotrophic. HSV1 can produce Herpes simplex encephalitis (HSE) and may be the only microorganism that specifically attacks the stellate and pyramidal cells of origin for the perforant pathway, producing an encephalitis with AD-like impairment of 
short-term memory $[95,96]$. Then again, HSE is a rare condition that affects children and adolescents as well as older people, with $50 \%$ of HSE cases being under age 50 [97]. Unlike sporadic AD, HSE shows no preference for the elderly. Abundant immunoreactivity was observed in temporal lobe regions of an encephalitis case. Large numbers of glia and neurons showed evidence of active infection. Similar HSV antigenicity is not observed in any temporal lobe region of AD cases or controls [98]. Approximately $70 \%$ of untreated HSE cases undergo rapid death [97] and 2.5\% regain normal brain function. Relapses of infections can occur within weeks or months [99]. These traits are uncharacteristic of $\mathrm{AD}$.

Proponents for HSV1 causality of AD describe a scenario in which HSV1 enters the brain in old age [84]. This late and rapid progression is inconsistent with the slow progression of $\mathrm{AD}$, in which brain changes gradually give rise to MCI and then to overt AD [100].

In summary, large AD transplantation studies carried out at the NIH failed to show evidence of transmissibility [80, 81]. Also, serum antibody titers measured in AD patients and non-demented controls for HSV, and other common viruses (Measles virus, Adenovirus, Coxiella burnettii, Cytomegalovirus, Influenza A, Influenza B, Chlamydia Group B (psittacosis virus), and Mycoplasma pneumoniae) have all failed to show statistically significant difference [93, 94]. Overall, the results indicate that, in the case of $\mathrm{AD}$, Koch's postulates have yet to be fulfilled by any infectious agent.

\section{Toxic metals}

Metal neurotoxicants have been suggested as environmental candidates for AD etiopathogenesis. Lead neurotoxicity preferentially affects children up to 4 years of age. One survivor of lead encephalopathy, who died at age 42 years with severe mental deterioration, had brain lead levels ten times higher than those of AD patients [101]. Nevertheless, the evidence for lead involvement in $\mathrm{AD}$ is scant.

Blood mercury levels were found to be twice as high in AD patients as in controls [102]. Most evidence relating to brain mercury levels in $\mathrm{AD}$ and human controls indicates that mercury does not progressively accumulate in human brains with increasing age as does aluminum [103, 104]. Aluminum best matches the profile for the AD environmental candidate.

Old age is commonly regarded as a major risk factor for AD. AD's long prodromal phase suggests that $\mathrm{AD}$ involves the slow and prolonged accumulation of a toxic agent in the brain over decades of time [26, 83]. If aluminum is indeed causal to $\mathrm{AD}$, its prolonged accumulation is likely to be life-long, with aluminum exposure beginning at, or even prior to, birth [105-107].

\section{ACUTE, SUB-ACUTE, AND CHRONIC FORMS OF ALUMINUM NEUROTOXICITY}

There are three main forms of aluminum toxicity (acute, sub-acute, and chronic). All three forms share some similarity and yet are significantly different from each other. They are similar is that they all cause some form of brain disease. The three forms differ in the type of subjects they affect. The rates at which these conditions occur and the aluminum concentrations involved are distinctly different.

\section{Acute aluminum neurotoxicity}

Acute aluminum neurotoxicity occurs when a large amount of aluminum (as much as $500 \mu \mathrm{g} / \mathrm{l}$ or more) enters the circulation. Acute aluminum neurotoxicity can affect humans with normal kidney function as well as those with chronic renal failure, resulting in an encephalopathy that typically involves grand mal seizures, culminating in coma and death within days or several weeks $[108,109]$.

\section{Sub-acute aluminum neurotoxicity}

Sub-acute aluminum neurotoxicity involves intermediate aluminum levels in blood or CSF over several years. An example is dialysis encephalopathy syndrome (DES) or dialysis dementia, a progressive encephalopathy that particularly affects dialysis patients with chronic renal insufficiency routinely exposed to high levels of circulating aluminum [110]. Dialysis patients have impaired ability to excrete the aluminum they acquire, mainly from aluminum-containing products such as phosphate binders, antacids, and/or contaminant aluminum in dialysis water. DES onset is insidious, often involving problems with speech. Seven to nine months after symptoms first appear, the patient becomes totally mute, unable to perform purposeful movements and soon dies.

DES epidemics have previously occurred in dialysis patients [110-112]. Removal of aluminum from the dialysis water and dialysis equipment, monitoring of plasma aluminum levels, and interventional treatments with aluminum-chelating agents, usually desferriox- 
amine, have prevented many adult deaths from this cause [113]. In general, DES and dialysis patients tend to be younger than most sporadic AD patients.

In a study by Harrington et al. [114], the mean brain aluminum content was $7.35 \mu \mathrm{g} / \mathrm{g}$ in dialysis patients compared to $1.95 \mu \mathrm{g} / \mathrm{g}$ in controls. Brain aluminum content correlated with plasma aluminum content $(r=0.772, p=0.008)$ and with terminally truncated tau protein in white matter $(r=0.753, p=0.001)$. Eight of 15 brains from dialysis patients exhibited A $\beta$ immunoreactivity. Electron microscopy revealed twisted filaments, indistinguishable from those in NFTs of AD brains, in two brains of dialysis patients with the highest levels of hyperphosphorylated tau in their gray matter [114]. The observed frequency for these AD-type changes exceeded the expected frequency for $\mathrm{AD}$ changes in this group (38-68 years; $0-1 \%, p<0.0001)$, corresponding to the expected frequency for $\mathrm{AD}$ only above age 80 .

Five of the six brains from dialysis patients with high aluminum showed depletion of normal tau accompanied by accumulation of hyperphosphorylated tau protein [114]. This phenomenon of progressive normal tau conversion to hyperphosphorylated tau also occurs in AD [115]. The tau-related changes reported in brains of these dialysis patients are comparable to those that occur in AD brains at an earlier stage and that eventually lead to NFT formation.

Some people feel that brains of dialysis patients with high plasma aluminum levels would have abundant NFTs if aluminum is involved in NFT formation in AD patients. However, given that chronic renal failure and $\mathrm{AD}$ are two distinctly different disease entities that develop at vastly different rates, their neuropathology can also be expected to differ. DES patients have very high brain aluminum concentrations (e.g., $25 \mu \mathrm{g} / \mathrm{g}$ brain tissue (dry weight)). This may result in aluminum precipitates, forming deposits in lysosomes of cells instead of reacting with hyperphosphorylated tau to form NFTs as aluminum does when present in plasma and brain concentrations 2-3 times higher than normal values.

NFT paucity in brains of dialysis patients and DES patients is also likely to relate to: (1) the age difference at which most patients develop chronic renal failure or sporadic $\mathrm{AD}$; (2) the sub-acute aluminum exposure period over which plasma levels in chronic renal failure patients are significantly elevated (amounting to a few years rather than four or more decades); and (3) the extremely slow, decades-long time over which human NFTs are estimated to form [22]. Dialysis patients may die of their condition prior to the time required for significant NFT formation unless treated by kidney transplantation.

NFTs also form very slowly in brains of non-human primates, even after aluminum injection directly into the brain [116]. In contrast, aluminum-induced NFTs develop in brains of rabbits and cats within 48 and 76 hours, respectively, after intracerebral aluminum injection $[117,118]$, showing species difference in the timing of NFT formation.

\section{Chronic aluminum neurotoxicity}

Finally, there is chronic aluminum neurotoxicity. Considerable evidence supports the possibility that $\mathrm{AD}$ is a form of chronic aluminum neurotoxicity that occurs in humans.

\section{ALUMINUM EXPOSURE AND ABSORPTION OF INGESTED ALUMINUM}

The main source of aluminum exposure for most humans is from oral ingestion of aluminum additives used to enhance various aspects of commerciallyprepared foods and beverages, including alum-treated drinking water [119]. In water treatment parlance, alum generally refers to aluminum sulfate $\left(\mathrm{Al}_{3}\left(\mathrm{SO}_{4}\right)_{3}\right)$, a relatively soluble form of aluminum used in the clarification of some bottled waters and many urban drinking water supplies.

Aluminum compounds have versatile properties and serve many useful functions as additives: anti-caking agents in salt, coffee whitener, pancake mix, and other powdered foods; emulsifiers and melting agents in cheeses; clarifying agents in water, puddings, and other processed foods where precipitates may form; pickling agents; meat binders for sausages and luncheon meats; hardening agents for candied fruits; gravy and sauce thickeners; rising agents in baking powder, self-rising flour, and baked goods; dough strengtheners; buffering and neutralizing agents; and mordants that bind dyes to confectioneries to make them colorful.

Aluminum absorption occurs across all parts of the intestine including the colon [120]. A major reason why aluminum accumulates so slowly in the brain is because most ingested aluminum is blocked from absorption into the systemic circulation by a mucus layer that lines the gastrointestinal tract [121].

Small amounts of $\mathrm{Al}^{26}$, a radioactive tracer for natural aluminum $\left(\mathrm{Al}^{27}\right)$, are detectable by accelerator mass spectrometry in the brains of rats within weeks after ingesting an equivalent amount of $\mathrm{Al}^{26}$ to the aluminum contained in a single glass of alum-treated 
drinking water [122-124]. $\mathrm{Al}^{26}$ is not found in nature so its presence in the brain after ${ }^{26} \mathrm{Al}$ treatment is unambiguous. Non-dietary sources of aluminum further contribute to the aluminum burden of the brain and skeletal tissues. Trans-dermal aluminum absorption occurs from topical applications (mainly aluminumbased deodorants and sunscreens) [125, 126]. Some injected vaccines include aluminum as an adjuvant to boost the body's immune response [127, 128]. Simulated vaccination in mice produces an aluminum peak in their brains 2-3 days post-injection [129]. Aluminum is a component of some pharmaceuticals (such as aluminum antacids and buffered aspirins) [130] and certain medical treatments such as irrigation of the bladder [131]. Aluminum is also contained in a bone cement used in surgery [132]. Additional information about human exposure to aluminum is available elsewhere [133, 134].

More aluminum enters than leaves the brain, resulting in a net accumulation of aluminum in the brain over time. Aluminum is the only common neurotoxicant known to accumulate in the brain with increasing age, even in non-demented humans albeit at lower rates [135-138]. In 2007, the UN/WHO expert committee on food additives reduced the provisional weekly tolerable level for aluminum from $7 \mathrm{mg} \mathrm{Al} / \mathrm{kg}$ bodyweight (bw)/week to $1 \mathrm{mg} \mathrm{Al} / \mathrm{kg}$ bw/week [139]. Many humans routinely consume considerably more aluminum than this recommended limit [133].

\section{METHODS THAT ALLOW POSTMORTEM ALUMINUM DETECTION IN BRAINS OF HUMANS AND EXPERIMENTAL ANIMALS}

Aluminum can be visualized postmortem in hippocampal and cerebral neurons of the $\mathrm{AD}$ brain [140] with at least three different staining techniques: the morin fluorescent stain [141], Walton bright field/fluorescent stain [142], a modified protocol for the Walton stain [143], and an immunostain against protein-bound aluminum [144, 145].

A variety of instrumentation is also available for aluminum detection or measurement. These include graphite furnace atomic absorption spectrometry, inductively-coupled plasma atomic emission spectrometry, laser microprobe mass analysis, scanning/transmission electron microscopy and transmission electron microscopy with energy-dispersive X-ray analysis, secondary ion mass spectrometry (SIMS), and accelerator mass spectrometry used in conjunction with the ${ }^{26} \mathrm{Al}$ radioisotope.
Aluminum is a light element present in the brain in small quantities. Some instrumental techniques, including nuclear microscopy, X-ray fluorescence, scanning electron microscopy with energy-dispersive $\mathrm{X}$-ray analysis (except in NFTs, where aluminum is more concentrated), and flame atomic emission methods are too insensitive to measure trace levels of aluminum in biological samples over the 1 to 7 parts aluminum per million ( $\mathrm{ppm}$ ) range contained in $\mathrm{AD}$ vulnerable brain regions. Also, certain other elements, mainly magnesium and phosphorus, can interfere with aluminum detection unless appropriate measures are taken to prevent this problem. Aluminum measurements require clean-room conditions.

\section{THE DILEMMA IN PERFORMING EPIDEMIOLOGICAL STUDIES THAT ASSESS THE EFFECTS OF CHRONIC HUMAN EXPOSURE TO A NEUROTOXIN}

The dilemma is that a properly-designed epidemiological study capable of providing the highest level of evidence that $\mathrm{AD}$ is a human form of chronic aluminum neurotoxicity would be unethical to perform. It would also be impossible to obtain cohorts of human subjects who could comply with a prospective, decades-long, randomized controlled trial involving assignment to treatment groups that consume either high, medium, or low concentrations of aluminum in their food and water, over several decades, to learn whether chronic aluminum ingestion results in AD. In lieu of any existing human study of this nature, the author applied a comparable protocol to an animal population.

\section{Rodents that mimic human dietary aluminum exposure}

Chronic aluminum neurotoxicity is best studied using human-equivalent aluminum exposure in shortlived laboratory animals over most of their lifespan $[41,143,146]$. A progressive dementia-like condition develops in a dose-dependent manner in rats that consume soluble aluminum in their drinking water for most of their adult life, in total amounts equivalent to those consumed by humans living in contemporary westernized societies from their foods, beverages, and aluminum additives [133, 134]. This approach mimics the aluminum dietary levels consumed by humans as well as the prolonged duration of human exposure to dietary aluminum. As it turned out, this animal model developed cognitive deterioration in old age after a long 

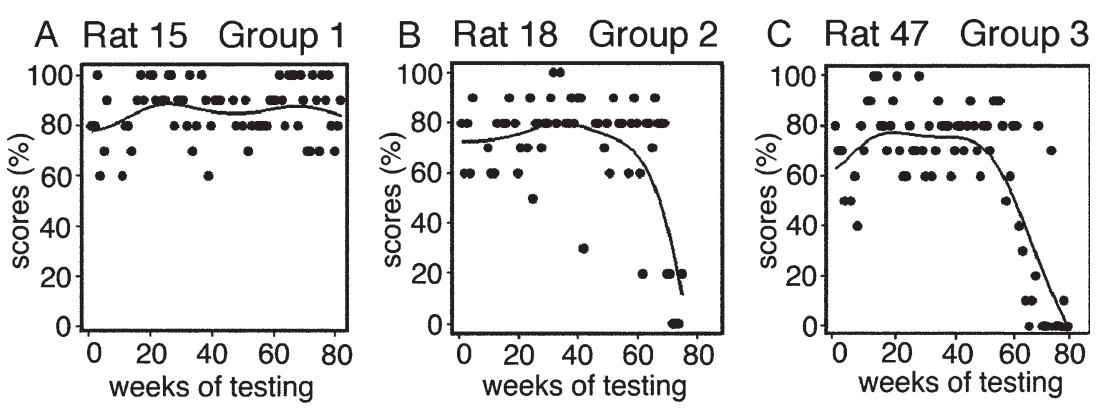

Fig. 5. Line and scatter plots, with Loess smoothing, exemplify overall T-maze performance scores of rats from the three aluminum treatment groups. Each dot recognizes one weekly test score for choice accuracy out of $100 \%$. A) Scores of a rat that chronically consumed a low level of aluminum in the human dietary aluminum range and remained cognitively-intact. B) Scores of a rat that exhibited cognitive deterioration after chronically consuming aluminum at an intermediate level. C) Scores of a rat with cognitive deterioration that chronically consumed aluminum equivalent to an amount at the high end of the human total dietary aluminum range. Reproduced from [145] with permission from Elsevier.

prodromal period and proved to be a faithful translational rat model for AD [41, 143].

Aluminum treatment was delayed until the rats were at age 12 months (commencing their middle age) to allow time for normal brain development. All animals in this longitudinal study were exposed to the same levels of aluminum in the air they breathed and in the measured food aliquots they received. The amounts of water the rats consumed ad libitum were also measured. The only treatment difference between the three rat groups was the amount of aluminum contained in their drinking water [146]. This level of controlled dietary aluminum exposure is more accurate than could be achieved with a human population.

\section{Training and weekly testing on a task used for memory assessment}

The rats were trained to perform a rewarded continuous alternation T-maze task commonly used for memory assessment [147]. Rats that died before 28 months of age, or were unable to perform all ten choices of the T-maze task within 5 minutes, were excluded from the study. The study rats were tested on the Tmaze task each week from age 9 months to the end of their natural lifespan. They performed the maze task with $70 \%-100 \%$ accuracy upon entering middle age (at 12 months).

All rats that consumed aluminum at the low end of the human dietary aluminum range performed the task in old age as well as, or better than, they had performed in middle age. Twenty percent of the rats that consumed aluminum at the intermediate dose level and seventy percent of those that consumed aluminum at the high dose level, that is, at the high end of the human total dietary aluminum range, obtained significantly lower mean T-maze performance scores in their old age (Fig. 5) than in their middle age and developed progressive cognitive deterioration from around ages 27-28 months. Their mean lifespan was 30 months of age.

Testing continued until a terminal condition became evident. The longest-living animals were tested on more than 100 occasions. The rats that developed cognitive deterioration in old age showed no evidence of improvement with continued testing, indicating that their condition was irreversible. These rats displayed abnormal neurological signs and exhibited novel behaviors such as confusion, attentional deficit, perseverative activity and urinary incontinence while in the T-maze. The rats that developed cognitive deterioration in old age did so in an aluminum dosedependent manner. Almost all rats in the study had normal kidney and liver functions in old age [146].

Rats that developed chronic aluminum neurotoxicity/cognitive deterioration generally did so at a mean age of age 28 months, after 16 months of chronic aluminum exposure at human relevant levels. Wistar rats are estimated to age approximately 35 times faster than humans [148] so 28 month old rats would approximate the age of 82-year old humans. The 16 month exposure period is almost equivalent to a human exposed to dietary aluminum for 47 years.

The amounts of aluminum the animals consumed correlated positively with their serum aluminum levels. Animals in the highest aluminum dose group had a mean serum aluminum level that was twice as high as that of the low aluminum controls yet some rats in the highest aluminum group had serum aluminum levels that were six times higher than the low aluminum controls. Two rats in the intermediate group had higher serum aluminum levels than other members of their 

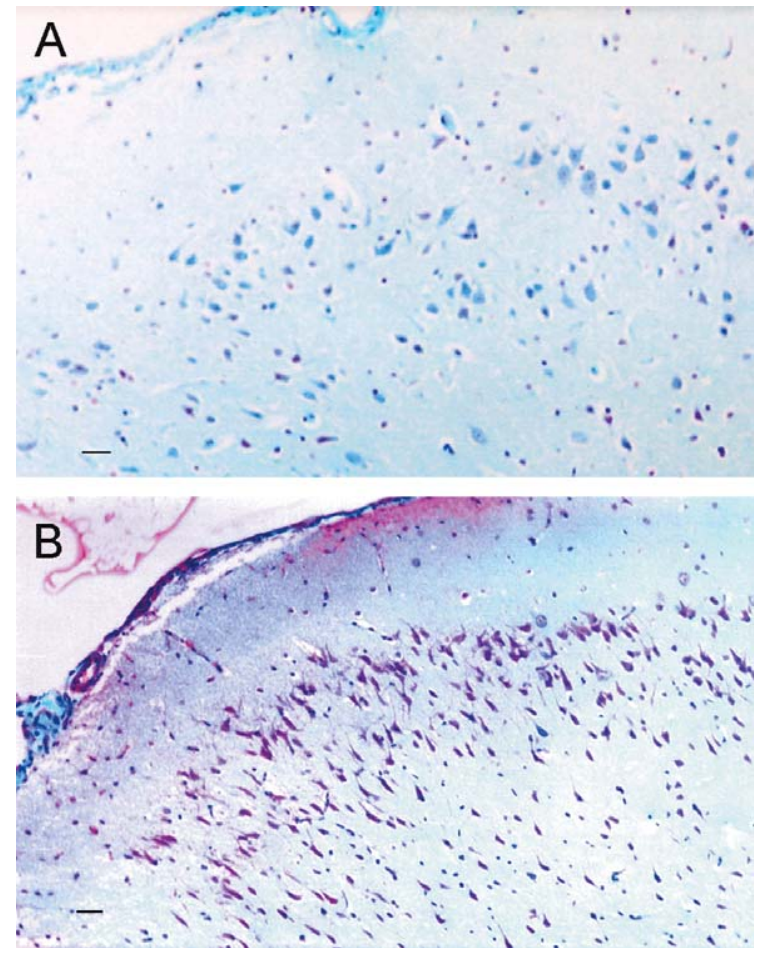

Fig. 6. Staining for aluminum in the entorhinal cortex of a cognitively-intact rat $(\mathrm{A})$ and a rat with cognitive deterioration (B). (A) Stellate and pyramidal cells of origin for the perforant pathway from a low aluminum control stain blue, lacking the magenta staining characteristic of aluminum with the Walton stain. Aluminum staining in this section primarily stains glial cells and erythrocytes. (B) In contrast, stellate and pyramidal cells of origin for the perforant pathway in the entorhinal cortex, from a rat with cognitive deterioration, stain magenta to purple, indicating high-stage aluminum accumulation. Reproduced from [149] with permission from the Royal Society of Chemistry.

treatment group. Those two rats were the only ones in their group to develop cognitive deterioration in old age, indicating they absorbed more aluminum than the others that consumed the same aluminum dose level. This may reflect some difference in their genetic constitution that enhances aluminum absorption [146].

\section{AD-equivalent neuropathology in the animal model for $A D$}

Neuropathological examination of sections processed with Walton's stain for aluminum [143] involved cell counts performed with image analysis software. These revealed that the superficial entorhinal cortex in brains from rats with cognitive deterioration had a significantly larger proportion $(60 \%)$ of pyramidal and stellate cells at stage IV aluminum accumulation compared to $23 \%$ at this stage in low aluminum controls [143]. These are the cells of origin for the perforant pathway (Fig. 6).

Also, high-stage nuclear aluminum accumulation affected a much larger proportion of the superficial entorhinal cortical cells than of cells in any other brain region examined. Cells in the hippocampal subiculum/CA1 zone tended to exhibit high stage aluminum accumulation in the form of discrete cell bands or lesions.

The temporal association cortex of rats with cognitive deterioration also had a significantly larger proportion $(40 \%)$ of neurons with high-stage aluminum accumulation than in the same brain region of controls (13\%) [143]. The temporal association cortex of cognitively-deteriorated rats also exhibited many more pyramidal cells with high stage aluminum accumulation than the primary sensory cortex. High-stage aluminum in the nucleus of the rats with cognitive deterioration preferentially affected the amygdala, olfactory bulb, piriform cortex, frontal cortex, nucleus basalis of Meynert, dorsal raphe nucleus, locus coeruleus, and other brain regions vulnerable to NFT damage in AD [146].

The brain regions most affected in this aluminuminducible translational rat model are homologous to those most affected in humans with AD [13, 146]. Cognitive deterioration in these rats involves destruction of the perforant pathway by a mechanism shared by humans with $\mathrm{AD}[1,29,41]$. In an earlier study, aluminum was directly injected into the brains of rabbits and NFT damage was observed in regions of the rabbit brains homologous to those where NFTs form in $\mathrm{AD}$ brains [150]. Other studies reported that dialysis patients exhibit aluminum deposition in the same brain regions that are vulnerable to NFTs in AD [43, $44,151]$. Thus, several models have shown that aluminum preferentially accumulates in brain regions that are particularly susceptible to damage in AD.

\section{AD PATIENTS ABSORB ALUMINUM EFFICIENTLY AND HAVE HIGHER PLASMA AND BRAIN ALUMINUM LEVELS THAN AGE-MATCHED NON-DEMENTED CONTROLS}

\section{Aluminum absorption and plasma aluminum levels in $A D$}

AD patients absorb about $64 \%$ more aluminum than age-matched controls from a standardized dietary 
aluminum dose [152]. Consequently, $\mathrm{AD}$ patients have higher plasma/serum aluminum levels than controls [153-159].

Down syndrome is commonly regarded as a model for accelerated AD. Down syndrome patients have even greater aluminum absorption than $\mathrm{AD}$ patients from a standardized aluminum dose. Down syndrome patients absorb approximately 6-fold more aluminum than age-matched controls from a standardized dietary aluminum dose and 4-fold more from a standardized pharmacological aluminum dose [160].

The reason(s) for increased aluminum absorption in $\mathrm{AD}$ patients and even more so in Down syndrome patients is unknown. The fact that Down syndrome patients absorb much more aluminum than agematched controls from a standardized dose suggests that the absorption difference could be attributable to an intestinal protein encoded by a gene on chromosome 21. A $\beta P P$ is on chromosome 21 and recent evidence indicates that A $\beta P P-d e f i c i e n t$ mice demonstrate impaired intestinal absorption [161]. A $\beta P P$ and $A \beta$ are both expressed in enterocytes [162], the absorptive epithelial cells of the small intestine, so they are candidates for elevating aluminum absorption. Aluminum has previously been shown to upregulate expression of the A $\beta P P$ gene [83] and stimulate A $\beta P P$ mRNA [163] expression in neural cells so aluminum may have the same effects on the A $\beta P P$ gene and mRNA expression in intestinal cells. A $\beta P P$ and/or $A \beta$ have yet to be tested to learn whether either or both are capable of enhancing aluminum absorption and, if so, the conditions under which this occurs. Regardless, higher levels of aluminum absorption give rise to higher brain aluminum levels [146].

\section{$A D$ and brain aluminum}

Aluminum has been regarded as a candidate cause of AD since 1973 when it was first shown that gray matter from brains of AD patients contains more aluminum than that of non-demented age-matched controls [135]. This finding has been confirmed by at least 11 reports from different researchers working in at least seven different countries using a variety of analytical techniques [104, 135, 143, 144, 164-170].

Aluminum concentrates in cell bodies localized in gray matter. When $\mathrm{AD}$ patients were initially reported to have higher brain aluminum levels than non-demented controls, the authors emphasized the importance of careful dissection to obtain 10-20 mg samples of gray matter for measurements of aluminum concentration. Samples larger than $20 \mathrm{mg}$ are likely to give erroneous results by diluting the sample with white matter that has lower aluminum content.

Two early studies were unable to confirm higher aluminum values in AD brains than in controls [136, 137]. The study by Markesbery et al. [137] utilized tissue samples ranging from 100 to $250 \mathrm{mg}$ (dry weight). Ganrot [171] described methodological flaws in both studies. Markesbery's group [137] subsequently revisited this issue, using conditions specified in the original report (20 mg (dry weight) sample sizes and more sensitive instrumentation) and then reported significantly higher aluminum values in biopsy samples of $\mathrm{AD}$ hippocampus, inferior parietal lobule, superior and middle temporal gyri than in controls [166]. Brain sections used as non-demented elderly controls in the McDermott study [136] were re-examined and found to contain abundant NFTs, indicating that their classification as controls was incorrect [172].

Aluminum values in gray matter of brains from aged, non-demented humans typically range from about 1 to $2.5 \mu \mathrm{g} \mathrm{Al} / \mathrm{g}$ brain tissue (dry weight) $[135,168]$. Aluminum values in gray matter of $\mathrm{AD}$ brain are 2- or 3 -fold higher, generally around 3 to $7 \mu \mathrm{g} \mathrm{Al} / \mathrm{g}$ brain tissue $[135,168]$. Approximately $20 \%$ of samples measured in AD-affected brain regions have aluminum values greater than $5.5 \mu \mathrm{g} \mathrm{Al} / \mathrm{g}$ brain tissue [104, 135]. Importantly, toxic effects occur in cats at cerebral aluminum concentrations between 4 and $6 \mu \mathrm{g} \mathrm{Al} / \mathrm{g}$ brain tissue [173]. Also, the $\mathrm{LD}_{50}$ (50\% lethality dose) for brain aluminum in rabbits is already evident at $5.5 \mu \mathrm{g}$ $\mathrm{Al} / \mathrm{g}$ brain tissue [172]. Aluminum combined with food acids, such as aluminum maltol (approved as a food additive in some countries), are much more toxic than poorly soluble inorganic aluminum compounds [172].

A $\beta P P / t a u$ triple-transgenic (3xTg-AD) [174] mice are reported to have higher aluminum levels in their brains than controls, even without aluminum supplementation [175]. It would be interesting to know if other untreated A $\beta P P$-transgenic animal models also have elevated aluminum levels in their brains which would imply more efficient aluminum absorption.

Down syndrome patients are reported to exhibit brain aluminum values as high as those in AD brains but at earlier ages [135]. Down syndrome patients generally show AD neuropathology by early middle age [176] and have a significantly higher rate of AD-type dementia than age-matched controls [177]. 


\section{PHYSICAL PROPERTIES OF ALUMINUM ACCOUNT FOR ITS NEUROTOXICITY}

The aluminum ion (abbreviated $\mathrm{Al}^{3+}$ ) has a high charge $(+3)$ and a very small ionic radius $(0.51 \AA)$ in its preferred coordination state with six water molecules. $\mathrm{Al}^{3+}$ is smaller than magnesium $\left(\mathrm{Mg}^{2+}\right)$ and slightly smaller than the ferric ion $\left(\mathrm{Fe}^{3+}\right)$ [178]. The size of $\mathrm{Al}^{3+}$ allows it to effectively compete in cells with the essential metals $\mathrm{Mg}^{2+}$ and $\mathrm{Fe}^{3+}$.

$\mathrm{Mg}^{2+}$ regulates more than 300 enzymes [179]. Nanomolar amounts of $\mathrm{Al}^{3+}$ successfully compete with $\mathrm{mM}$ amounts of $\mathrm{Mg}^{2+}$, substituting for $\mathrm{Mg}^{2+}$ in the active sites of some key regulatory enzymes, including protein kinase $\mathrm{C}$, and in ATP and GTP co-factors. In this way, $\mathrm{Al}^{3+}$ alters, and impairs, the activities of key regulatory proteins and cellular signaling pathways [180,181 (review)]. $\mathrm{Al}^{3+}$ also substitutes for $\mathrm{Fe}^{3+}$ in Tf and on IRP2 [182, 183].

$\mathrm{Al}^{3+}$ competes with $\mathrm{Mg}^{2+}, \mathrm{Fe}^{3+}$, ferrous iron $\left(\mathrm{Fe}^{2+}\right)$, and calcium $\left(\mathrm{Ca}^{2+}\right)$ for cell ligands, particularly phosphates. $\mathrm{Al}^{3+}$ also competes with $\mathrm{Ca}^{2+}$ ions for their sites on membranes and in calcium channels [184-186].

The high charge:size ratio of $\mathrm{Al}^{3+}$ causes it to dissociate from ligands very slowly, approximately $10^{8}$ times more slowly than $\mathrm{Ca}^{2+}$ and $10^{4}$ times more slowly than $\mathrm{Mg}^{2+}$ [178]. The slow ligand exchange rates of $\mathrm{Al}^{3+}$ prevent $\mathrm{Al}^{3+}$ from successfully participating in enzyme reactions as they require rapid dissociation. Hence, $\mathrm{Al}^{3+}$ disrupts cell metabolism, largely by interfering with the activity of key regulatory enzymes and cell signaling processes $[180,182]$.

Another aspect of $\mathrm{Al}^{3+}$ toxicity is its pro-oxidant status. $\mathrm{Al}^{3+}$ produces oxidative stress on its own and synergistically with copper and iron [187-189]. These neurotoxic features of aluminum severely incapacitate neuronal function rather than killing cells outright.

\section{ALUMINUM INVOLVEMENT IN DEMENTIAS OTHER THAN AD}

High aluminum levels in dialysate water have elevated brain aluminum levels in dialysis patients and caused multiple cases of DES or dialysis dementia [111, 190, 191]. Aluminum levels in the brains of untreated DES patients have exceeded $25 \mu \mathrm{g} / \mathrm{g}$ in brain tissue with death occurring within months to several years [191].
Aluminum has also been implicated in other dementias; namely, Balint's disease from occupational aluminum exposure [192], amyotrophic lateral sclerosis/parkinsonism dementia complex of Guam [193, 194], and Parkinson's disease with AD-type dementia [195]. Furthermore, aluminum is the acknowledged cause of cognitive impairment in hundreds of Canadian miners who inhaled McIntyre powder over years in a prophylactic attempt to reduce their chance of developing lung silicosis. The number of miners who became cognitively impaired correlated in a time-dependent manner with their length of exposure to McIntyre powder; i.e., from 0.5 to 10 years, $10-20$ years or more than 20 years [196]. McIntyre powder consists of poorly soluble aluminum hydroxide and pulverized (metallic) aluminum.

\section{EVIDENCE FOR ALUMINUM INVOLVEMENT IN AD PATHOGENESIS}

The studies that follow, including some based on transgenic animal models and others on wild-type animal models, replicate what appear to be the most important neuropathological aspects of AD.

\section{NFT formation}

\section{Protein phosphatase $2 A$ activity and $m R N A$} levels are diminished in $A D$, resulting in hyperphosphorylation of cytoskeletal proteins

AD brains show depressed activity of protein phosphatase 2A (PP2A), the main enzyme in mammalian brain that removes phosphates from phosphorylated tau [197], and abnormally low mRNA levels for PP2A [198]. The low PP2A activity in AD brains results in hyperphosphorylation of cytoskeletal proteins (in particular, hyperphosphorylated tau and hyperphosphorylated neurofilament protein) in pyramidal cells and on NFTs [199-206]. Inhibited PP2A activity resulting from a PP2A mutation in transgenic mice also correlates inversely with increased levels of hyperphosphorylated protein [207].

In AD brains, intracellular NFTs at an early stage of NFT formation are reported to stain more intensely for hyperphosphorylated neurofilament protein and less for hyperphosphorylated tau. At later stages, the NFTs stain more intensely for hyperphosphorylated tau and less for hyperphosphorylated neurofilament protein [199]. Some authors [200] have suggested that phosphorylated neurofilament protein participates in the formation of human NFTs by serving as a scaffold 
for tau deposition since hyperphosphorylated neurofilament immunoreactivity appears in patterns (linear skeins, flame-shaped, or intraneuronal globose skeins) very similar to those of silver-stained NFTs. Ultrastructural immunocytochemical studies have shown that antigenic determinants in the $200-\mathrm{kDa}$ neurofilament protein, Bodian's silver-binding sites in the carboxyl-terminal tailpieces of neurofilament subunits and microtubule-associated proteins, especially tau, are all integral components of the filaments that constitute the NFTs of AD brains [201]. These authors note that NFT filaments comprise sequences from both tau and neurofilament proteins in a hyperphosphorylated form.

Several studies, for example, that by KsiezakReding et al. [208], have reported that immunostaining for hyperphosphorylated neurofilaments in NFTs is artifactual, resulting from antibodies that are crossreactive for both neurofilament and tau proteins. Vickers et al. [202] analyzed the report by KsiezakReding and colleagues, noting that those authors had used inappropriately small dilutions to demonstrate cross-reactivity between neurofilament and tau proteins. Vickers et al. observed that faint crossreactivity to tau was just visible in an immunoblot assay with the SM1310 neurofilament antibody if its concentration was higher than that normally used. However, cross-reactivity for native tau was absent when all three of their antibodies for hyperphosphorylated neurofilaments (SM1310, SM 132, and M14) were used at appropriate dilutions. Also, Vickers et al. used a double-labeled immunostaining technique that revealed NFTs are immunoreactive both for hyperphosphorylated tau and for hyperphosphorylated neurofilament protein [202].

Down syndrome patients likewise exhibit a dramatic decrease in PP2A levels which correlates inversely with elevated levels of hyperphosphorylated tau [209] and hyperphosphorylated neurofilament protein [210].

\section{Aluminum inhibits PP2A activity in vitro and in vivo, resulting in hyperphosphorylation of cytoskeletal proteins}

Aluminum inhibition of PP2A activity results in the in vitro formation of hyperphosphorylated tau, the key protein of mature NFTs [211]. Aluminum-inhibited PP2A activity also results in the accumulation of hyperphosphorylated tau in brains of wild-type rats exposed to human-equivalent levels of aluminum for most of their adult life [146, 212], suggesting that aluminuminduced inhibition of PP2A activity may also explain the increases of hyperphosphorylated tau that occur in brains of aluminum-exposed renal dialysis patients [114], Down syndrome patients [209], and AD patients [115].

Immunostaining evidence indicates that relatively small amounts of aluminum are sufficient to inhibit PP2A activity in neurons. Evidence for this is contained in serial sections of CA1 pyramidal cells from the brains of wild-type rats chronically exposed to aluminum at human-equivalent levels [212]. Immunostained sections show CA1 cells with abundant amounts of hyperphosphorylated tau. CA1 cells in adjacent sections stained for aluminum are mostly at intermediate stages (II-III) of aluminum accumulation [212]. Small amounts of hyperphosphorylated tau are just visible in some neurons equivalent to those with stage I aluminum accumulation.

Aluminum inhibition of PP2A activity leads to the accumulation of hyperphosphorylated cytoskeletal proteins in neurons of humans, rats, rabbits and in vitro experimental systems [114, 115, 211-219]. Nascent intracellular tangles, recently induced by aluminum in rabbit brain, initially exhibit phosphorylated and non-phosphorylated neurofilament protein [215, 216]. Over the next few days, the rabbit tangles change, gradually developing epitopes of hyperphosphorylated tau, A $\beta P$, A $\beta, a_{1}$-antichymotrypsin, and ubiquitinprotein conjugates [219]. Hence, NFTs that are rapidly induced in certain animal brains by intracerebral aluminum injection evolve to resemble human NFTs [199] more than commonly acknowledged.

A consequence of tau hyperphosphorylation induced by aluminum in neurons is that the excess phosphate interferes with tau's ability to bind to microtubules. This increases the level of soluble hyperphosphorylated tau in the cytoplasm [220]. The cell continues to produce more normal tau, which soon becomes hyperphosphorylated, contributing to the increasing accumulation of hyperphosphorylated tau. Aluminum causes hyperphosphorylated tau to aggregate into granules of increasing size while sparing normal tau [218].

Around this stage, caspase truncates hyperphosphorylated tau [221] in AD cells. Aluminum activates caspase 3 [222, 223], the same type of caspase involved in tau truncation [221, 224]. Since aluminum activates caspase 3, inhibits PP2A activity [211, 212], thereby promoting the accumulation of hyperphosphorylated tau, and is present in AD cells where NFTs form, aluminum may also participate in caspase-induced truncation of hyperphosphorylated core tau in these cells. 
Aluminum induces the formation of NFTs from hyperphosphorylated tau in brains of humans, particularly those with $A D$

I. At the pre-tangle stage, aluminum avidly binds to phosphates on the hyperphosphorylated tau, causing this form of tau to aggregate, precipitate, and form granules of increasing size in AD hippocampal and cortical neurons [218, 225] (Fig. 7A, B).

II. By the late pre-tangle stage, the aggregated granules have coalesced to form a homogeneous, confluent cytoplasmic mass that stains for both aluminum and hyperphosphorylated tau [225] (Fig. 7C, D)

III. At an early tangle stage, nascent filaments can be seen within the otherwise homogeneous aluminum/hyperphosphorylated tau complex (Fig. 7E, F).

IV. As more filaments precipitate within the complex, they grow and form NFTs that continue to stain for both aluminum and hyperphosphorylated tau [225] (Fig. 7G, I).

These NFTs are the markers used by neuropathologists to identify $\mathrm{AD}$-affected brain regions involved in AD progression. The aluminum component of NFTs has been confirmed by several different types of instruments $[169,170]$ as well as staining techniques. Some iron is also found in NFTs [67], suggesting that NFTs are a cell-protective response, involving sequestration of potentially-toxic free metal ions. Aluminum binding to growing NFTs in the neuronal cytoplasm may be a cellular mechanism for slowing aluminum uptake into the nucleus where aluminum avidly binds to nucleic acids and chromatin [225].

Only a portion of the large CA1 neurons in ADaffected human brains, and aluminum-exposed rabbits, form NFTs [225, 226], indicating that the conditions for NFT formation are rather specific. For species reasons, NFTs are absent from virtually all aged rat neurons, even in those that contain abundant amounts of aluminum and hyperphosphorylated tau [212]. Instead, aged rat hippocampal and cortical neurons show various stages of nuclear aluminum accumulation as do many hippocampal and cortical neurons of aged humans (Fig. 8) and aluminum-exposed rabbits [140, 143, 226].

It would be rare for any single animal model to replicate all aspects of a complex disease like AD. For example, A $\beta P P$ - and tau-transgenic mice are useful models for understanding amyloidogenesis and tauopathies, respectively, in that they focus on replicating a specific $\mathrm{AD}$ hallmark rather than $\mathrm{AD}$ progression.
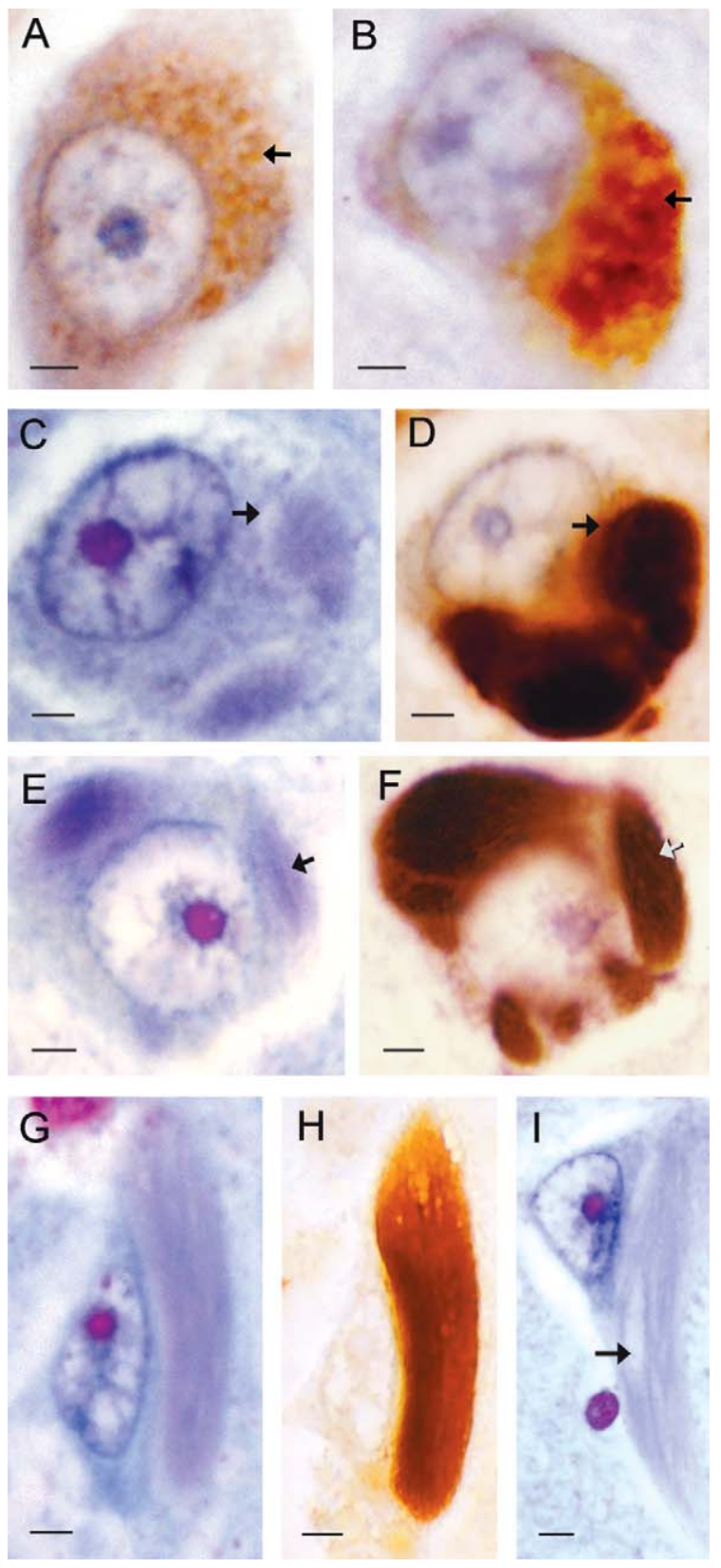

Fig. 7. NFT formation in AD-affected hippocampus of human brain. A, B) Pre-tangle pyramidal cells stained for hyperphosphorylated tau show (A) small and (B) larger (fused) granules (arrows). C, D) Cytoplasmic pools form from granule fusion and stain for $(C)$ aluminum and (D) hyperphosphorylated tau. Arrows mark the thinner margins of the cytoplasmic pools that consist of an Al/hyperphosphorylated tau complex. E, F) Thin filamentous structures just visible in the cytoplasmic pools, stained for (E) aluminum and (F) hyperphosphorylated tau, represent nascent filaments that develop into NFTs. G, $\mathrm{H})$ Mature NFTs continue to stain for $(\mathrm{G})$ aluminum and $(\mathrm{H})$ hyperphosphorylated tau. I) A large NFT stained to show aluminum (pale purple filaments) has consumed the cytoplasmic pool so individual filaments are more clearly seen (arrow). $\mathrm{MB}=7 \mu \mathrm{m}$ for $\mathrm{A}-\mathrm{H} ; 3 \mu \mathrm{m}$ for I. Reproduced from [225] with permission from IOS Press. 

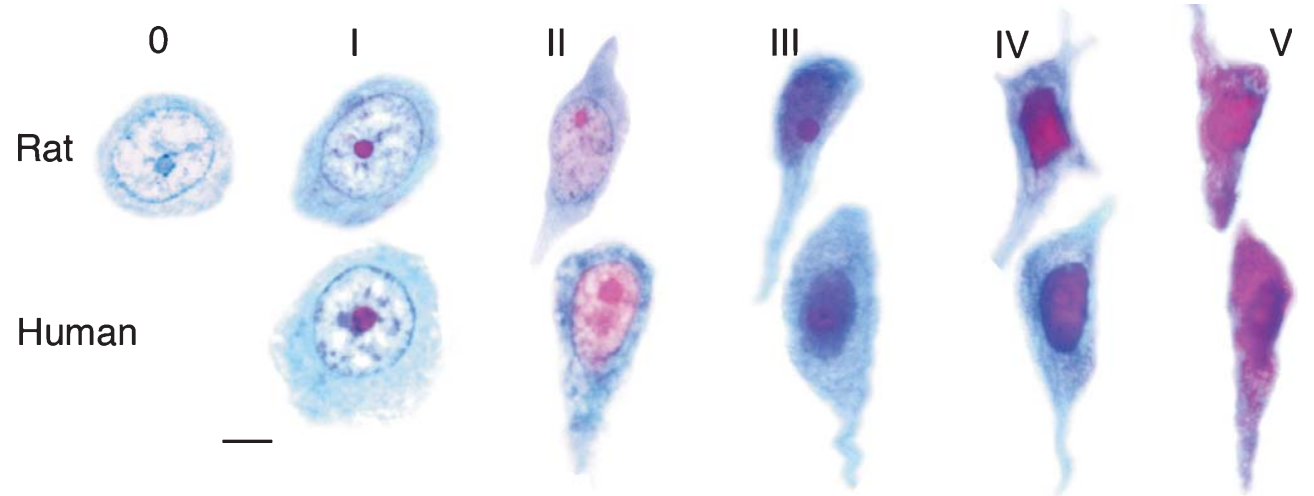

Fig. 8. Stages of aluminum accumulation in rat and human hippocampal pyramidal neurons. Stage 1: All sections of hippocampal pyramidal neurons from older human brain, that contain a visible nucleolus, exhibit at least stage I aluminum accumulation (staining only the nucleolus). Stage I neurons have a normal shape. Stages II and III: The nucleoplasm progressively deepens in hue, appearing pink at stage II and purple at stage III. The nucleus and overall cell shape show subtle shrinkage and dendritic changes. Stage IV: Aluminum in the nucleus appears bright magenta. The cell is obviously shrunken and its neurites appear tortuous and retracted. At stage V, aluminum is distributed throughout the nucleus and cytoplasm. These cells are deformed but appear to be viable, exhibiting neither necrosis nor apoptosis. Magnification bar $=5 \mu \mathrm{m}$. Reproduced from [143] with permission from Elsevier.

The aging aluminum-based rat model is valuable in that it replicates key aspects of AD clinical and neuropathological progression. That is, aluminum specifically produces severe neuropathological damage to the cells of origin for the perforant pathway and hippocampal pyramidal cells in the rats that developed cognitive deterioration. Damage to these cells and brain regions in humans with $\mathrm{AD}$ isolates the hippocampus from the neocortex and impairs memory function [25, 29, 227].

Hippocampal isolation can logically explain the cognitive deterioration that occurred in a substantial proportion of the rats that chronically consumed aluminum at the high end of the human total dietary aluminum range. The rats with cognitive deterioration had severely impaired memory function and they displayed other AD-type behaviors and neurological signs $[41,143,146]$. Furthermore, the sequence of damage in their brains parallels that which occurs with AD progression. The superficial entorhinal cortex was most damaged, followed by other limbic regions and neocortical association areas - in that order - and, to a much lesser extent, motor and primary sensory areas. The animal model replicates cell damage in the sequence of brain regions involved in $\mathrm{AD}$ progression.

As for AD hallmarks, the aging aluminum-based rat model for $\mathrm{AD}$ shows incipient changes in $\mathrm{A} \beta$ and NFT formation. These changes seldom if ever develop into mature plaques and tangles, clearly a result of species differences. However, aluminum participation in the formation of $A \beta$ and $A \beta$ plaques is described below
[228] and this paper has already addressed aluminum participation in human NFTs [225]. The aluminuminduced rat model shows neuropathology that can account for dendritic/axonal dieback, synapse loss, and cortical atrophy, including that which appears on MRI scans analyzed for AD progression [143].

\section{High stage aluminum accumulation in cells and its consequences}

High stage aluminum accumulation refers to intense staining for aluminum in the cell nucleus (Stage IV) or throughout the nucleus and cytoplasm (stage V) (Fig. 8) [143]. The available evidence indicates that aged corticocortical cells with high stage aluminum accumulation, whether in the form of NFTs or nuclear aluminum, are drastically different cells from their healthier counterparts that exhibit low-stage aluminum accumulation, both with respect to structure and function.

An electrophysiological consequence of Al-induced NFT formation in neurons that normally discharge at high spontaneous frequencies is that they become electrically inactive [173]. Human neurons with NFTs have low cytochrome oxidase activity [229]. Low concentrations of aluminum inhibit mitochondrial cytochrome c oxidase activity. Low cytochrome c oxidase activity indicates a low metabolic rate, suggesting these cells are no longer capable of neuronal function [230, 231]. Dysfunctional human cells with NFTs are able to survive in this diminished condition in brain tissue for decades [232]. Dysfunctional cells with high 

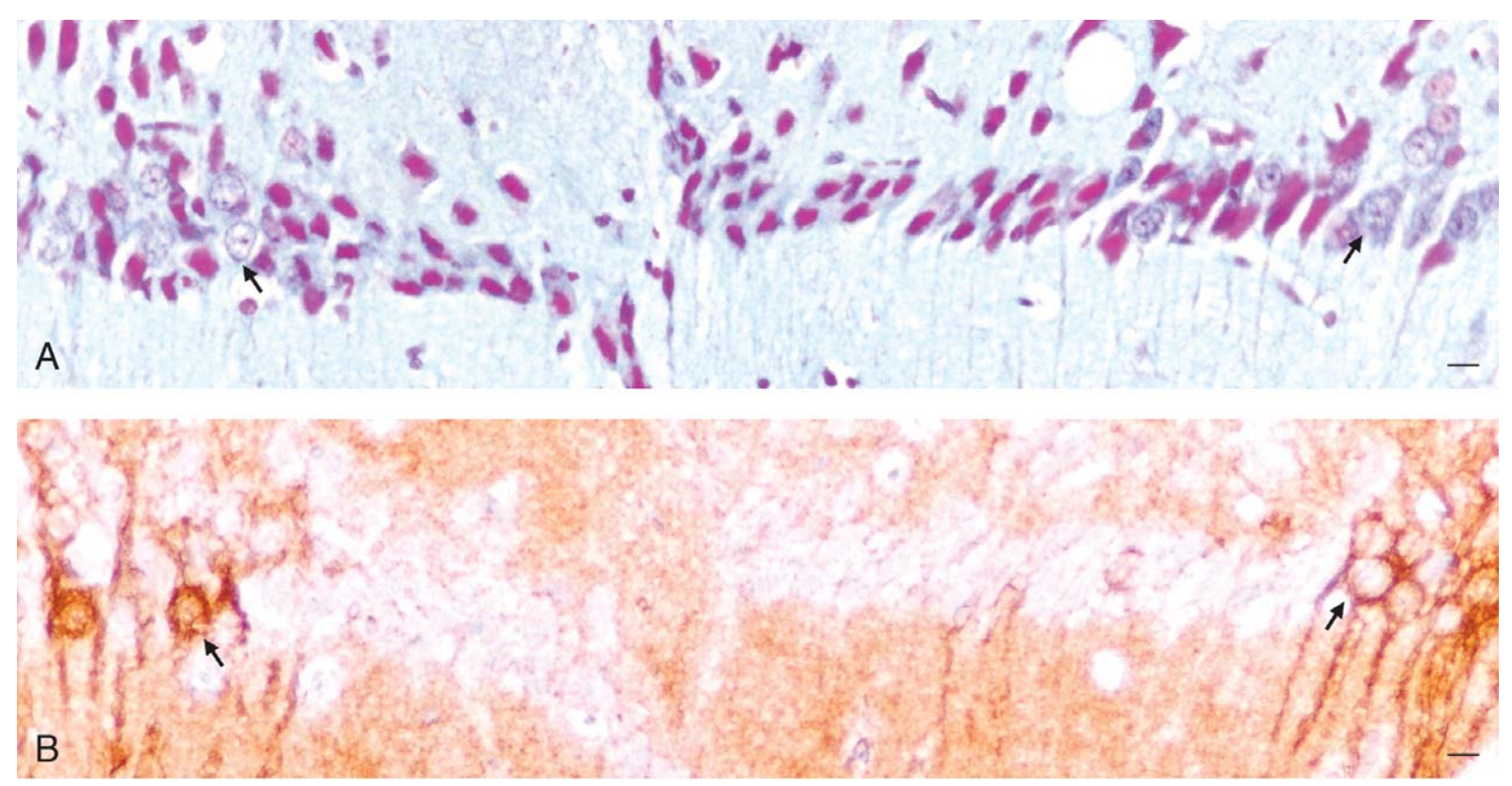

Fig. 9. High stage aluminum accumulation correlates with microtubule depletion in rat cortical and hippocampal cells. A) Stage IV pyramidal cells stain magenta for nuclear aluminum within a hippocampal CA1 lesion of an aged rat with cognitive deterioration. Pyramidal cells with a more normal appearance (arrow) are seen at the margins of the lesion. B) An adjacent section immunostained for acetylated- $\alpha$-tubulin shows that cells within the same lesion fail to immunostain for microtubules whereas microtubules can be clearly seen in the more normal cells along the margins of the lesion (arrow). Magnification bars $=10 \mu \mathrm{m}$. Reproduced from [143] with permission from Elsevier.

stage nuclear aluminum accumulation likewise persist in animal brains for a prolonged time [143].

Human and/or rat pyramidal cells that exhibit NFTs or high stage nuclear aluminum accumulation consistently show microtubule depletion (Fig. 9) [143, 233, 234]. Aluminum-induced microtubule depletion leads to: shrinkage and change in cell shape [140, 143]; impaired axonal transport [163, 235]; dendritic/axonal dieback [143, 236, 237]; and significant loss of synapse density [143, 238, 239]. Dieback results in shrinkage of the cell's dendritic tree (Fig. 10) that normally accounts for $95 \%$ of cell volume [240]. Widespread dieback leads to significant cortical atrophy [241] that becomes increasingly extensive as $\mathrm{AD} / \mathrm{chronic}$ aluminum neurotoxicity spreads more widely, in a chain reaction that involves increasing numbers of brain regions.

\section{Aluminum involvement in granulovacuolar degeneration (GVD)}

Simchowicz, one of Alzheimer's students, reported that hippocampal cells of AD tissue show GVD [242]. This pathological feature consists of clusters of intracytoplasmic vacuoles, measuring up to $5 \mu$ in diameter, that each contain a single dense

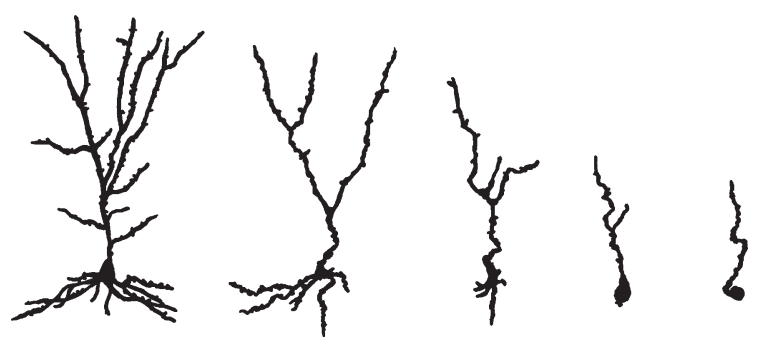

Fig. 10. Camera lucida drawings of AD Golgi-stained pyramidal cells illustrating the process of dendritic/axonal dieback (left to right). Redrawn from [241] with permission from Elsevier.

granule, 0.5 to $1.5 \mu$ across. GVD occurs in most AD patients, affecting 9-66\% of hippocampal pyramidal cells [243]. Granules in the vacuoles of human hippocampal neurons stain for aluminum [140] and exhibit an aluminum peak when examined by energy dispersive X-ray microanalysis spectroscopy [244]. GVD granules also stain for altered proteins, mainly caspase-cleaved A $\beta P P$ and hyperphosphorylated tau. GVD formation is experimentally induced in hippocampal cells of rats chronically exposed to dietary aluminum at human-equivalent levels [146, 212] or by repeated intraperitoneal injections of 


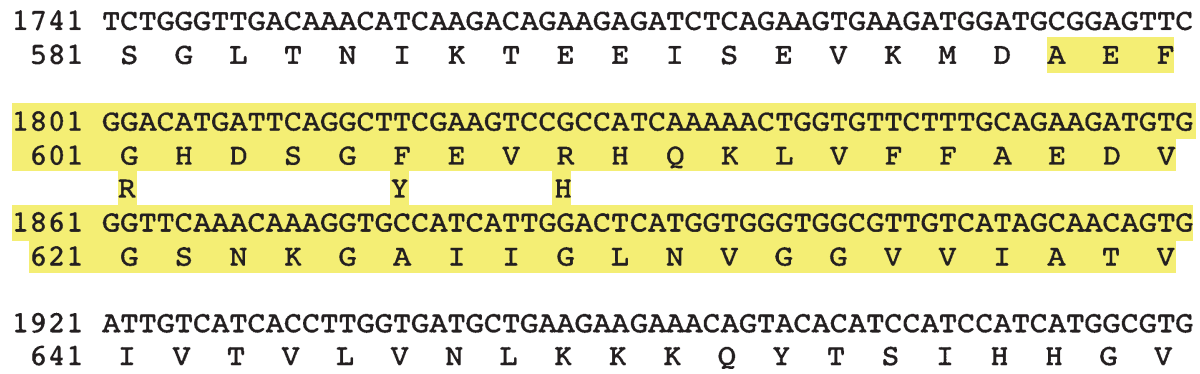

Fig. 11. The $A \beta$ portion of the rat $\mathrm{A} \beta \mathrm{PP}$ sequence. The protein sequence is shown in the standard one-letter code below the nucleotide sequence. The rat equivalent of the human $A \beta$ polypeptide is located between amino acid residues 598-640 and is shown in gray. Also bold/highlighted are the three positions $(601,606$, and 609) where the rat and human sequences differ. The human amino acid residues are indicated below the rat amino acid residues at these positions. The highlighted residues indicate the presumed transmembrane region. Reproduced from [256] with permission from the Nature Group.

aluminum [245]. Aluminum appears to be the only agent reported to experimentally induce GVD. GVD also occurs together with NFTs in amyotrophic lateral sclerosis/parkinsonism dementia of Guam [193, 246], another neurodegenerative disease that involves chronic aluminum neurotoxicity.

\section{Aluminum involvement in A $\beta$ metabolism}

A $\beta$ deposits develop under multiple conditions: as part of the degenerative process in regions of brain where terminals are deteriorating [29]; in association with some blood vessels [247]; and in response to oxidative stress [228]. Aluminum is present in large corticocortical neurons of AD patients [140] and can interact with $A \beta$ at various stages of its formation in experiments. Hence, aluminum may interact with $A \beta$ in the same way in elderly human brains.

\section{Aluminum upregulation expression of the $A \beta P P$ gene, its $m R N A$ and protein}

Aluminum upregulates gene expression for A $\beta P P$ and other stress-response proteins in human neural cells [83]. A $\beta P P$ mRNA and A $\beta P P$ protein expression are increased in the brains of rats chronically exposed to aluminum levels equivalent to those consumed by humans [163]. Aluminum induces axonopathy in hippocampal and cortical regions of rat and rabbit brains in

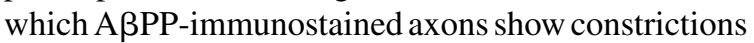
and varicosities, indicating impaired axonal transport $[163,235]$.

\section{Aluminum alters $A \beta P P$ cleavage to form $A \beta$ instead of $s A \beta P P \alpha$}

$\mathrm{A} \beta \mathrm{PP}$ is cleaved by $\alpha$-secretase at a site that results in the formation of $\mathrm{sA} \beta \mathrm{PP} \alpha$ which is neurotrophic, providing that phosphorylation by protein kinase $\mathrm{C}$ (PKC) has occurred [249, 250]. This cleavage precludes the formation of $A \beta$. However, aluminum, at a concentration of only $2 \times 10^{-8} \mathrm{~mol} / \mathrm{L}$, inhibits $90 \%$ of PKC activity [251]. Thus, a small amount of intraneuronal aluminum has the potential to redirect $\mathrm{A} \beta \mathrm{PP}$ cleavage from its non-amyloidogenic pathway (forming $\mathrm{SA} \beta \mathrm{PP} \alpha$ ) to its amyloidogenic pathway (forming $A \beta)$. This can explain why exposure of cultured rat neurons to 10-50 $\mu \mathrm{M}$ aluminum for three weeks results in a pronounced increase in soluble $A \beta$ in addition to tau accumulation and neurite degeneration [252].

\section{Aluminum interactions with $A \beta$}

Aluminum forms complexes with $\mathrm{A} \beta$ in vitro and stabilizes $A \beta$ oligomers [253]. Aluminum also converts soluble human $A \beta_{42}$ with random-coil structure to a fibrillar precipitate with $\beta$-pleated structure [254, 255 ] and induces human $A \beta$ fibrils to aggregate [248]. A $\beta$ fibrillization is a species-specific effect that occurs in animal species that have the same amino acid sequence for $A \beta$ as in humans. The $A \beta$ sequence of rats and mice differs from the $A \beta$ sequence for humans by three amino acids (Fig. 11) [256]. This species-specific difference is apparently sufficient to block soluble $A \beta$ from fibrillizing and forming $A \beta$ plaques in mouse and rat brains [235, 256].

\section{Aluminum accelerates and enhances A $\beta$ plaque formation in a transgenic mouse model for amyloidogenesis}

Mice have been genetically-engineered to overexpress human $\mathrm{A} \beta \mathrm{PP}$ and to form human $\mathrm{A} \beta$. This allows $\mathrm{A} \beta$ plaques to form in brains of relatively young transgenic mice. Human A $\beta$ PP-transgenic mice, fed a diet 
supplemented by aluminum for one year, exhibited significantly higher levels of plasma $\mathrm{A} \beta$ as well as soluble and fibrillar forms of $A \beta$ in their brains [228]. $\mathrm{A} \beta$ plaque formation occurred earlier and in appreciably larger amounts in brains of aluminum-exposed transgenic mice than in brains of a transgenic cohort without aluminum supplementation. Thus, aluminum stimulates the formation of $A \beta$, both in oligomeric and plaque forms, in the brains of A $\beta P P$-transgenic mice that express human $\mathrm{A} \beta \mathrm{PP}$ and the human $\mathrm{A} \beta$ peptide. An implication of this study is that the presence of aluminum in AD brains could likewise stimulate the formation of human $A \beta$.

Congophilic amyloid angiopathy (CAA), a common accompaniment to $A D$, involves $A \beta$ deposits in cortical blood vessels. $A \beta$ also deposits in the walls of cortical vessels of mice that have drunk water containing alum for at least one year, serving as a model for CAA in humans [257]. The first neuropathological examination of a person overexposed to alum from the Camelford water pollution incident, who died of an unspecified neurological condition, was determined to have a rare form of sporadic early-onset CAA in leptomeningeal and cerebral cortical vessels. High concentrations of aluminum were found in severelyaffected cortical regions of this patient's brain [258].

\section{Aluminum in $A \beta$ plaque cores}

A recent study by Yumoto et al. [259] using transmission electron microscopy with an ultrasensitive spectrometric technique reported that aluminum is detectable in the cores of $\mathrm{A} \beta$ plaques. The present author used histological processes to find aluminum in AD neurons and NFTs. It is clear that ultrasensitive highly sophisticated precision techniques such as that of Yumoto need to be brought to bear to determine the presence of minute amounts of aluminum in plaques and the significance of that presence.

A different group, using a prototype nuclear microscope, reported 15 years earlier that aluminum is absent from $A \beta$ plaques [260]. A paper published by the latter authors on the same subject in the following year [261] contained discrepancies; for example, reporting their nuclear microscope had a resolution of $50 \mathrm{ppm}$ compared to the $15 \mathrm{ppm}$ resolution reported in the previous year. The nuclear microscope has yet to be validated for its ability to detect aluminum in histological tissue sections. Regardless, Kawahara et al. report that aluminum concentrations lower than $15 \mathrm{ppm}$ are sufficient to aggregate $\mathrm{A} \beta$ [248].
Aluminum induces the formation of a presenilin-2 variant that increases $A \beta_{42}$ and disrupts signaling in the hippocampal CA1 field of sporadic $A D$ brains

The AD research community has long focused on a search for mutations in three main candidate genes: those for A $\beta P P$, presenilin-1, and presenilin-2. The presumed defect would enhance $A \beta_{42}$ levels in the brain and distinguish sporadic AD cases from nondemented controls. A presenilin-2 gene product that satisfies these requirements was identified by a group of researchers around the turn of the 21 st century [262, 263].

This gene product comes from an inducible, alternatively-spliced variant of the presenilin-2 gene designated PS2V rather than from a mutant gene. The exon 5 sequence is omitted during transcription of the PS2 gene [262]. The shortened mRNA that encodes $\mathrm{PS} 2 \mathrm{~V}$ is truncated at its $\mathrm{N}$-terminus. PS2V is reported to be present in the brains of all sporadic AD cases examined by the authors and absent from $90 \%$ of brains from non-demented controls [263]. PS2V increases $\mathrm{A} \beta_{42}$ production by affecting A $\beta P P$ cleavage [262]. $\mathrm{PS} 2 \mathrm{~V}$ also interferes with A $\beta P P$ maturation and disrupts the signaling pathway for the unfolded protein response, particularly in the hippocampal CA1 field where PS2V is associated with dendritic dieback [263].

PS2V expression is inducible in cultured cells by hypoxia and can be blocked by antioxidants. This suggested to the authors that the PS2V isoform could be induced by a metal that causes oxidative damage. Neuroblastoma cells were exposed to copper chloride, copper sulfate, zinc chloride, ferrous chloride, ferric chloride, aluminum chloride, and aluminum maltolate to learn whether they might be involved in PS2V formation. Aluminum (both as the chloride and maltolate salts) is the only metal that consistently induces the PS2V isoform and does so at a low $(25 \mu \mathrm{M})$ aluminum concentration (Al) [264].

\section{Inflammation in an aluminum-based animal model for $A D$}

Aluminum salts contained in drinking water, at amounts to which humans are routinely exposed, were found to increase cerebral levels of glial activation and inflammatory cytokines as well as increasing the level of A $\beta P P$ within brains of mice [265]. AD is known to be a mild inflammatory condition associated with elevating basal levels of inflammation markers. 


\section{ALUMINUM AND THE FEATURES PROPOSED TO INCREASE CELL SUSCEPTIBILITY TO NFT FORMATION}

\author{
Aluminum, large cell size, and complexity
}

Histological stains and SIMS analyses for aluminum in brain tissue from AD cases and animal models for $\mathrm{AD}$ reveal that aluminum preferentially accumulates in large corticocortical cells of the entorhinal cortex, hippocampal CA1 field, subiculum, amygdala, and neocortical pyramidal cells with long corticocortical projections in layers III and V [41, 140, 143, 146, $150,151]$.

Aluminum and high levels of metabolic activity, transferrin receptors, and iron uptake

Aluminum metabolism is closely intertwined with iron metabolism. The close physical resemblance between $\mathrm{Al}^{3+}$ and $\mathrm{Fe}^{3+}$ ions (charge density, ionic size, and favored coordination number) allows $\mathrm{Al}^{3+}$ to mimic $\mathrm{Fe}^{3+}$ in plasma and cells. Cellular proteins involved in iron transport and iron uptake into cells are somewhat promiscuous in that they fail to discriminate between $\mathrm{Fe}^{3+}$ and $\mathrm{Al}^{3+}$. This may explain why approximately $90 \%$ of plasma aluminum binds to unoccupied iron-binding sites on Tf, circulating as Tf-aluminum, with the remainder binding to albumin and low molecular weight species such as citrate [266, 267].

Aluminum utilizes endothelial Tf receptors, evolved for iron uptake, to cross the blood-brain barrier [49, 268] and neuronal $\mathrm{Tf}$ receptors for entering large complex neurons [53]. Aluminum has at least three modes for uptake into neurons: (1) trans-synaptic transport between interconnected neurons; (2) Tfmediated endocytosis; and (3) mechanisms involved in Tf-independent iron uptake (Tf-IU) [269]. Aluminum preferentially deposits in large cells with high metabolic demands, high densities of $\mathrm{Tf}$ receptors on their plasma membrane surface, and high iron uptake to meet those metabolic demands [50].

\section{Aluminum accumulation in neurons leads to iron disregulation}

Iron homeostasis becomes disregulated in AD brains as a result of IRP2 stabilization in large neurons (Fig. 12A). Micromolar amounts of aluminum (4 to $20 \mu \mathrm{M} \mathrm{Al}$ ) successfully compete with $\mathrm{Fe}^{3+}$ for iron-binding sites on IRP2. This stabilizes IRP2 and prevents its degradation. According to Yamanaka et al. [183], the affinity of $\mathrm{Al}^{3+}$ for these iron-binding sites

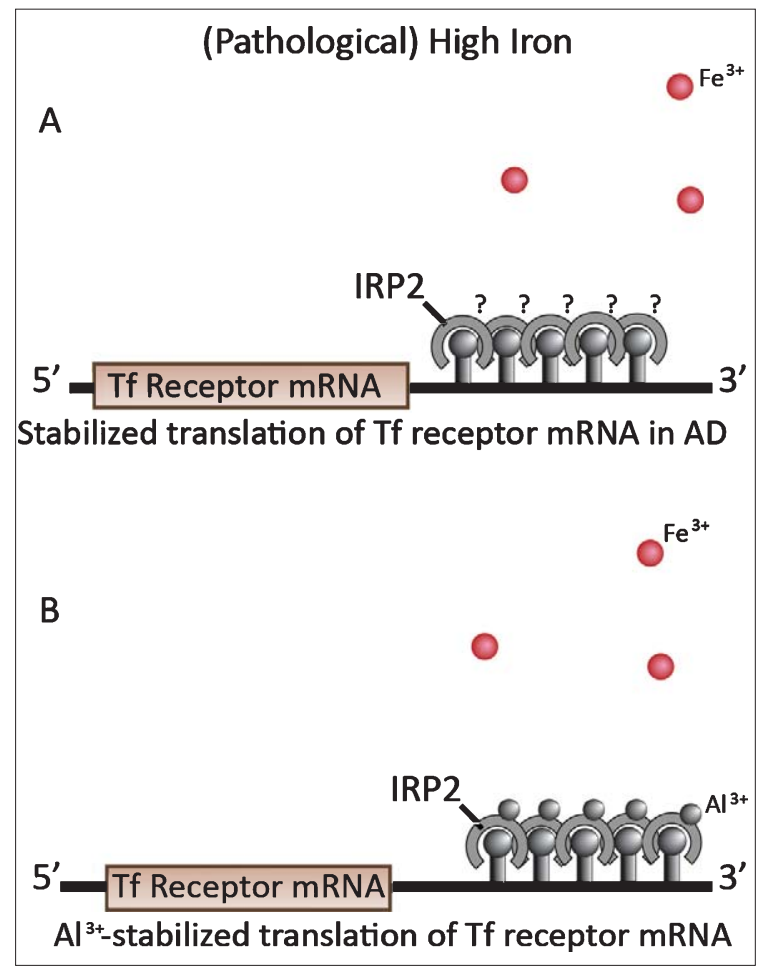

Fig. 12. Stabilized translation of Tf receptor mRNA under pathological circumstances. A) $\mathrm{Fe}^{3+}$ ion oxidation of IRP2 does not occur in AD-affected neurons despite high iron levels. This results in stabilized translation of $\mathrm{Tf}$ receptor mRNA and continuation of iron and aluminum uptake. B) Aluminum ions bind to $\mathrm{Fe}^{3+}$ ion-binding sites on IRP $2 s$ of aluminum-exposed neurons, preventing $\mathrm{Fe}^{3+}$ ions from oxidizing the IRP2s and signaling for IRP2 destruction. This results in the stabilized translation of Tf receptor mRNA and continuation of iron and aluminum uptake. In AD and aluminum exposed cells, IRP1 behaves in its normal manner (see Fig. 3C and D).

is much higher than for other metals, including iron. Aluminum-induced stabilization of IRP2 prevents IRP2 oxidation and degradation in the ubiquitinproteosomal pathway (Fig. 12B). This allows IRP2 to stay bound to the mRNA for Tf receptors which in turn allows $\mathrm{Tf}$ receptor production to continue and ferritin synthesis to remain suppressed as though the affected cells were permanently iron-deficient $[62,63]$. Aluminum-induced stabilization of IRP2 is consistent with the IRP2 stabilization that occurs in AD [65] and may account for this phenomenon. In contrast, IRP1 is unaltered by aluminum exposure or $\mathrm{AD}[65,183]$.

In vitro and in vivo evidence both attest to aluminum's effects on iron metabolism. Intraneuronal aluminum accumulation enhances iron uptake and expression of hyperphosphorylated tau in neuroblastoma cells [270]. A kinetic radiolabelled Tf-Fe binding 
assay showed the number of surface Tf receptors per cell was higher in cells cultured in the presence of aluminum than in those without aluminum exposure [271]. This increase in Tf receptor numbers probably reflects aluminum-induced stabilization of IRP2.

Rats given a series of thrice weekly intraperitoneal injections of aluminum gluconate over 8 weeks ("aluminum-loading") showed dramatically increased brain aluminum levels, ranging between 14 to $25 \mu \mathrm{g} / \mathrm{g}$ (wet weight) in AD-vulnerable brain regions. The high aluminum levels were paralleled by increased iron levels in the same regions, including 4- to 9-fold iron increases in the temporal, frontal, and parietal cortices and a 4-fold iron increase in the hippocampus of aluminum-exposed rats compared to iron levels in untreated controls [272]. These results suggest that the subtle rise in brain iron stores that occurs for some time with increasing age $[103,273]$ may be secondary to the increase that occurs in brain aluminum levels over time [135-138].

\section{Aluminum, iron, and oxidative stress}

Aluminum produces oxidative damage on its own and synergistically with iron. Intracellular aluminum forms an aluminum-superoxide complex that produces oxidative damage $[187,274]$ and aluminum also enhances iron-initiated oxidative damage [187, 275]. Brain cells have a limited ability to react to oxidative stress, particularly in view of their relatively low levels of glutathione and glutathione peroxidase.

Aluminum-loading for eight weeks significantly increases levels of lipid peroxidase while decreasing superoxide dismutase and glutathione peroxidase levels even further. Iron elevation on its own is unable to produce consistent change in any of the cytoprotective enzymes (superoxide dismutase, glutathione reductase, glutathione peroxidase, and catalase) [272].

Aluminum stabilizes intracellular ferrous iron by preventing its oxidation to ferric iron $[275,276]$. Ferrous iron reacts with hydrogen peroxide, driving the highly toxic Fenton reaction that generates reactive hydroxyl radicals that increase oxidative stress. Aluminum stabilization of the ferrous iron is an important mechanism for enhancing iron-induced free radical production and oxidative stress [276].

\section{Aluminum and myelination}

Myelin sheaths provide insulation for nerve fibers, allowing impulses to transmit quickly and efficiently along the length of the axon. A poorly-myelinated neuron with a leaky axon needs to generate vastly more energy to compensate for its axonal wastage. The entry of aluminum and excess iron into the poorly-myelinated neurons of the entorhinal cortex, hippocampus, and other limbic regions could render these neurons susceptible to significant peroxidative stress and its oxidative consequences-oxidized fats and proteins, leading to the formation of reactive aldehydes and carbonyls, cross-linking of proteins, nucleic acids, and proteins with nucleic acids [277, 278].

\section{Aluminum and vascularization}

Tf receptor densities on capillary endothelium are 6 to 10 times greater than those on neurons [279]. The vascular plexus that surrounds stellate and pyramidal cell islands of the superficial entorhinal cortex invests the islands with dense capillary networks [1]. In principle, larger amounts of aluminum should be removable from the plasma by these dense capillary networks and transferred into the extracellular matrix surrounding the cells of the superficial entorhinal cortex than in regions where capillaries are less abundant. Increased amounts of extracellular aluminum would then be available to plasma membrane Tf receptors for uptake into neurons. This may be a reason why aluminum preferentially accumulates in the entorhinal cortex early in $\mathrm{AD}$ and why these cells are damaged to a greater extent than cells of other limbic regions.

\section{ALUMINUM AND AD PROGRESSION}

Aluminum can spread from one brain region to another via interconnected corticocortical cells. Gelfoam ${ }^{\circledR}$ impregnated with $15 \%$ aluminum lactate or $5 \%$ aluminum chloride was implanted into the nasal cavity of rabbits [280]. One month later, high aluminum levels and neuropathological changes were observed in the olfactory bulb, pyriform cortex, hippocampus, and cerebral cortex. This study demonstrates that soluble forms of aluminum can enter the processes of olfactory neurons in the nasal mucosa and move across pyramidal cell synapses in both retrograde and anterograde directions [26].

Aluminum spread to different brain regions via interconnected corticocortical cells, together with aluminum-inhibited PP2A activity which results in hyperphosphorylated tau, can logically account for the "spread of hyperphosphorylated tau" reported to occur between interconnected corticocortical cells [35-37]. It would be prudent to stain for aluminum, in investigations into the spread of hyperphosphorylated tau, to 
ensure aluminum absence before assuming that hyperphosphorylated tau is acting on its own. Aluminum spread between interconnected cells could also contribute towards the spread of NFTs and microtubule depletion in AD-affected brain regions [14, 143].

\section{SUGGESTED SCENARIO FOR ALUMINUM INVOLVEMENT IN AD PROGRESSION}

Aluminum ingestion and absorption is an ongoing process in contemporary society as is aluminum uptake into the brain [133]. Dietary aluminum can thus fuel the spread of aluminum over time into an increasing number of brain regions. Minute amounts of aluminum progressively enter neurons via Tf receptors, under normal control of the IRPs, throughout the long prodromal phase.

Intraneuronal aluminum spreads between stellate and pyramidal corticocortical cells of the superficial entorhinal cortex, within islands and between islands, and from these entorhinal cortical cells into connecting corticocortical cells of the hippocampal CA1/subiculum zone, olfactory bulb, neocortex, amygdala, and other brain regions with which the entorhinal cortex communicates. The amount of aluminum provided by projections from the entorhinal cortex to interconnected corticocortical cells in other brain regions could be proportional to their connections.

More than midway through the prodromal period, aluminum accumulation in entorhinal cortical stellate and pyramidal cells begins to reach neurotoxic levels. At this point, intracellular aluminum levels are sufficiently high to compete with essential metals, to inhibit PP2A activity, and disrupt iron metabolism. Cellular IRP2 levels become stabilized and their iron metabolism is disregulated, showing an increased density of $\mathrm{Tf}$ receptors on their surface. The disregulated entorhinal cortical cells continue to import aluminum and iron from the neuropil, exporting these metals directly into connecting cells without obvious restraints on this process.

Neurons require tau protein for microtubule assembly and microtubule stabilization. The activity of tau protein depends on alternating phosphorylation and dephosphorylation reactions. Kinases continue to phosphorylate tau but PP2A activity is now too low in these cells to remove phosphate groups. This situation leads to cytoplasmic accumulation of hyperphosphorylated cytoskeletal proteins; in particular, hyperphosphorylated tau [281-283].
Hyperphosphorylated tau is unable to bind to microtubules so microtubule assembly cannot proceed and existing microtubules break down. Consequently, cells that develop hyperphosphorylated tau, including those in which NFTs form, become microtubuledepleted [233, 234]. Microtubule depletion results in dendritic/axonal dieback, de-efferentation, and deafferentation of the superficial entorhinal cortical cells. Dieback of cell processes, and neuron death in regions where abundant NFTs form, appear in MRI scans as gray matter atrophy.

Meanwhile, aluminum aggregates the soluble hyperphosphorylated tau that occurs in some cells [218], forming granular precipitates which fuse to form larger granules. Eventually, the large granules also fuse to form cytoplasmic pools of the aluminum/hyperphosphorylated tau complex out of which filaments and NFTs precipitate. The NFTs mature, slowly growing as they acquire more aluminum and more hyperphosphorylated tau (Fig. 8G-I). Very large NFTs eventually denucleate their host cells which consequently die and leave the NFTs behind [140].

Such destruction of the entorhinal cortical cells of origin for the perforant pathway, which bi-directionally interconnects the hippocampal formation with the rest of the cortex, results in isolation of the hippocampus, ultimately leading to the memory defects and confusion that herald the onset of overt $\mathrm{AD}$ [25, 29, 227].

The disease continues to spread to corticocortical cells in other brain regions, exhibiting the same types of pathology and functional loss as in regions affected at an earlier stage. In time, the transformation of neurons into dysfunctional cells becomes extensive in some AD-affected regions. Microtubule-depleted corticocortical cells in tissues with slower aluminum accumulation and more slowly-growing NFTs, can survive for decades in the dysfunctional state [232]. Microtubule-depleted cells are unable to contribute to neural function. These cells are unable to sustain their high cytochrome oxidase activity [44, 229]. Most of their chromatin is in the heterochromatin form (compacted DNA with reduced transcription) [278]. As each of the regions involved in AD progression becomes affected by these changes, their specialized functions diminish to the extent that their large neurons are damaged.

The scenario presented here is consistent with the atrophy of gray matter that occurs over time with AD progression as described by the Braak hierarchical model, MRI/VBM clinical trials and other neuropathological studies. 


\section{CONCLUSIONS}

This paper describes studies that have endeavored to define the sequence of interconnected brain regions affected in $\mathrm{AD}$, either by MRI/VBM or neuropathological techniques. There is a consensus among these investigators that $\mathrm{AD}$ spreads in a stepwise manner along well-defined corticocortical connections from the entorhinal cortex to other limbic regions in the medial temporal lobe, followed by the temporoparietal association cortices, and then frontal and occipital cortices, and via corticosubcortical connections to the nucleus basalis of Meynert and to susceptible brainstem nuclei.

From the major proposed candidates as the environmental component for $\mathrm{AD}$, aluminum provides the best fit. Aluminum preferentially accumulates in the cells of origin for the perforant pathway of the entorhinal cortex and other large corticocortical cells prone to NFT formation in specific brain regions of $\mathrm{AD}$ patients and in rats with aluminum-induced cognitive deterioration.

The main reason for aluminum deposition in $\mathrm{AD}$ affected brain regions is that $\mathrm{AD}$-affected brain regions have large neurons with high metabolic activity and high iron requirements. Aluminum ions are very similar in size and charge to ferric iron ions. The problem is that endothelial cells of the blood-brain barrier and these large neurons are unable to distinguish between the essential iron ions and non-essential toxic aluminum ions that they take in via their transferrin receptors. Eventually, the concentration of intraneuronal aluminum ions can be sufficient to disrupt iron regulation, further increasing iron and aluminum uptake. Aluminum participates in NFT formation in AD-affected neurons of the hippocampus, entorhinal cortex and other NFT-affected brain regions.

Other factors that may help to explain why the entorhinal cortex is one of the earliest- and most severely-affected brain regions in $\mathrm{AD}$ are: (1) the entorhinal cortex is poorly myelinated; and (2) the entorhinal cortex has abundant and redundant vascularization that could increase its exposure to plasma aluminum to a greater extent than in other less wellvascularized limbic regions.

This article also describes aluminum contributions to AD neuropathology: to A $\beta P P$ and $A \beta$ metabolism; NFT formation and growth; and to GVD. Given that aluminum can spread along the olfactory pathway from neuron to neuron, a scenario has been constructed to show how aluminum could spread between interconnected cells that make up the AD progression sequence and, in principle, spread more widely as AD progresses throughout the brain.

\section{ACKNOWLEDGMENTS}

The author is grateful to Don Bryson-Taylor for his editorial assistance and to Dirce Everett for her scientific illustrations.

The author's disclosure is available online (http:// www.j-alz.com/disclosures/view.php?id=1637).

\section{REFERENCES}

[1] Van Hoesen GW, Augustinack JC, Dierking J, Redman SJ, Thangavel R (2000) The parahippocampal gyrus in Alzheimer's disease: Clinical and preclinical neuroanatomical correlates. Ann NY Acad Sci 911, 254-274.

[2] Pearson RCA (1996) Cortical connections and the pathology of Alzheimer's disease. Neurodegeneration 5, 429-434.

[3] Räihä I, Kaprio J, Koskenvuo M, Rajala T, Sourander L (1996) Alzheimer's disease in Finnish twins. Lancet 347, 573-578.

[4] Nee LE, Eldridge R, Sunderland T, Thomas CB, Katz D, Thompson CB, Weingartner H, Weiss H, Julian C, Cohen R (1987) Dementia of the Alzheimer type: Clinical and family study of 22 twin pairs. Neurology 37, 359-363.

[5] Pedersen NL, Gatz M, Berg S, Johansson B (2004) How heritable is Alzheimer's disease late in Life? Findings from Swedish twins. Ann Neurol 55, 180-185.

[6] Ashburner J, Friston KJ (2000) Voxel-based morphometry - The methods. Neuroimage 11, 805-821.

[7] Honea RA, Swerdlow RH, Vidoni ED, Burns JM (2011) Progressive regional atrophy in normal adults with a maternal history of Alzheimer disease. Neurology 78, 822-829.

[8] Whitwell JL, Przybelski SA, Weigand SD, Knopman DS, Boeve BF, Petersen RC, Jack CR Jr (2007) 3D maps from multiple MRI illustrate changing atrophy patterns as subjects progress from mild cognitive impairment to Alzheimer's disease. Brain 130, 777-786.

[9] Thompson PM, Mega MS, Woods RP, Zoumalan CI, Lindshield CJ, Blanton RE, Moussai J, Holmes CJ, Cummings JL, Toga AW (2001) Cortical change in Alzheimer's disease detected with a disease-specific population-based brain atlas. Cereb Cortex 11, 1-16.

[10] Cupples LA, Farrer LA, Sadovnick AD, Relkin N, Whitehouse P (2004) Estimating risk curves for firstdegree relatives of patients with Alzheimer's disease: The REVEAL study. Genet Med 6, 192-196.

[11] Risacher SL, Shen L, West JD, Kim S, McDonald BC, Beckett LA, Harvey DJ, Jack CR Jr, Weiner MW, Saykin AJ, Alzheimer's Disease Neuroimaging Initiative (ADNI) (2010) Longitudinal MRI atrophy biomarkers: Relationship to conversion in the ADNI cohort. Neurobiol Aging 31, 1401-1418.

[12] Mizuno K, Wakai M, Takeda A, Sobue G (2000) Medial temporal atrophy and memory impairment in early stage of Alzheimer's disease: An MRI volumetric and memory assessment study. J Neurol Sci 173, 18-24.

[13] Braak H, Braak E (1991) Neuropathological stageing of Alzheimer-related changes. Acta Neuropathol 82, 239-259.

[14] Pearson RCA, Esiri MM, Hiorns RW, Wilcock GK, Powell TP (1985) Anatomical correlates of the distribution of the 
pathological changes in the neocortex in Alzheimer disease. Proc Natl Acad Sci U S A 82, 4531-4534.

[15] Arnold SE, Hyman BT, Flory J, Damasio AR, Van Hoesen GW (1991) The topographical and neuroanatomical distribution of neurofibrillary tangles and neuritic plaques in the cerebral cortex of patients with Alzheimer's disease. Cereb Cortex 1, 103-116.

[16] Kovács T, Cairns NJ, Lantos PL (1999) Beta-amyloid deposition and neurofibrillary tangle formation in the olfactory bulb in aging and Alzheimer's disease. Neuropathol Appl Neurobiol 25, 481-491.

[17] Kovács T, Cairns NJ, Lantos PL (2001) Olfactory centres in Alzheimer's disease: Olfactory bulb is involved in early Braak's stages. Neuroreport 12, 285-288.

[18] Ulrich J (1985) Alzheimer changes in nondemented patients younger than sixty-five: Possible early stages of Alzheimer's disease and senile dementia of Alzheimer type. Ann Neurol 17, 273-277.

[19] Price JL, Morris JC (1999) Tangles and plaques in nondemented aging and "preclinical" Alzheimer's disease. Ann Neurol 45, 358-368.

[20] Parvisi J, Van Hoesen GW, Damasio A (2001) The selective vulnerability of brainstem nuclei to Alzheimer's disease. Ann Neurol 49, 53-66.

[21] Josephs KA, Whitwell JL, Ahmed Z, Shiung MM, Weigand SD, Knopman DS, Boeve BF, Parisi JE, Petersen RC, Dickson DW, Jack CR Jr (2008) Beta-amyloid burden is not associated with rates of brain atrophy. Ann Neurol 63, 204212.

[22] Braak H, Del Tredici K (2011) The pathological process underlying Alzheimer's disease in individuals under thirty. Acta Neuropathol 121, 171-181.

[23] Gertz H-J, Xuereb J, Huppert F, Brayne C, McGee MA, Paykel E, Harrington C, Mukaetova-Ladinska E, Arendt T, Wischik CM (1998) Examination of the validity of the hierarchical model of neuropathological staging in normal aging and Alzheimer's disease. Acta Neuropathol 95, 154-158.

[24] Yassa MA, Muftuler LT, Stark CEL (2010) Ultrahighresolution microstructural diffusion tensor imaging reveals perforant path degradation in aged humans in vivo. Proc Natl Acad Sci U S A 107, 12687-12689.

[25] Van Hoesen GW, Hyman BT, Damasio AR (1991) Entorhinal cortex pathology in Alzheimer's disease. Hippocampus 1, 1-8.

[26] Saper CB, Wainer BH, German DC (1987) Axonal and transneural transport in the transmission of neurological disease: Potential role in system degenerations, including Alzheimer's disease. Neuroscience 23, 389-398.

[27] De Lacoste M, White CL (1993) The role of cortical connectivity in Alzheimer's disease pathogenesis: A review and model system. Neurobiol Aging 14, 1-16.

[28] Braak H, Del Tredici K (2011) Alzheimer's pathogenesis: Is there neuron-to-neuron propagation? Acta Neuropathol 121, 589-593.

[29] Hyman BT, Van Hoesen GW, Kromer LJ, Damasio AR (1987) Perforant pathway changes and the memory impairment of Alzheimer's disease. Ann Neurol 20, 472-481.

[30] Geddes JW, Hyman BT, Van Hoesen GW, Kromer LJ, Damasio AR (1986) Perforant pathway changes and the memory impairment of Alzheimer's disease. Ann Neurol 20, 472-481.

[31] Hardy J, Allsop D (1991) Amyloid deposition as the central event in the aetiology of Alzheimer's disease. Trends Pharmacol Sci 12, 383-388.
[32] Braak H, Braak E (1997) Frequency of stages of Alzheimerrelated lesions in different age categories. Neurobiol Aging 18, 351-357.

[33] Li X, Messe A, Marrelec G, Pelegrini-Issac M, Benali H (2010) An enhanced voxel-based morphometry method to investigate structural changes: Application to Alzheimer's disease. Neuroradiology 52, 203-213.

[34] Duychaerts C (2011) Tau pathology in children and young adults: Can you still be unconditionally baptist? Acta Neuropathol 121, 145-147.

[35] Liu L, Drouet V, Wu JQ, Witter MP, Small SC, Clelland C, Duff K (2012) Trans-synaptic spread of tau pathology in vivo. PLoS One 7, e31302.

[36] Lace G, Savva GM, Forster G, de Silva R, Brayne C, Matthews FE, Barclay JJ, Dakin L, Ince PG, Wharton SB, MRC-CFAS (2009) Hippocampal tau pathology is related to neuroanatomical connections: An ageing population-based study. Brain 132, 1324-1334.

[37] de Calignon A, Polydoro M, Suarez-Calvet M, William C, Adamowicz DH, Kopeikina KJ, Pitstick R, Sahara N, Ashe KH, Carlson GA, Spires-Jones TL, Hyman BT (2012) Propagation of tau pathology in a model of early Alzheimer's disease. Neuron 73, 685-697.

[38] Kristensson K (1978) Retrograde transport of macromolecules in axons. Ann Rev Pharmacol Toxicol 18, 97-110.

[39] Holtzman E (1977) The origin and fate of secretory packages, especially vesicles. Neuroscience $2,327-355$.

[40] Vale RD, Reese TS, Sheetz MP (1985) Identification of a novel force-generating protein, kinesin, involved in microtubule-based motility. Cell $\mathbf{4 2}, 39-50$

[41] Walton JR (2012) Cognitive deterioration and associated pathology induced by chronic low-level aluminum ingestion in a translational rat model provides an explanation of Alzheimer's disease, tests for susceptibility and avenues for treatment. Int J Alzheimers Dis 2012, 914947.

[42] Stranahan AM, Mattson MP (2010) Selective vulnerability of neurons in layer II of the entorhinal cortex during aging and Alzheimer's disease. Neural Plasticity 2010, 108190.

[43] Morris CM, Candy JM, Oakley AE, Taylor GA, Mountfort S, Bishop H, Ward MK, Bloxham CA, Edwardson JA (1989) Comparison of the regional distribution of transferrin receptors and aluminium in the forebrain of chronic renal dialysis patients. J Neurol Sci 94, 295-306.

[44] Morris CM, Candy JM, Bloxham CA, Edwardson JA (1990) Brain transferrin receptors and the distribution of cytochrome oxidase. Biochem Soc Trans 18, 647-648.

[45] Braak H, Del Tredici K, Schultz C, Braak E (2000) Vulnerability of select neuronal types to Alzheimer's disease. Ann NY Acad Sci 924, 53-61.

[46] Morrison BM, Hof PR, Morrison JH (1998) Determinants of neuronal vulnerability in neurodegenerative diseases. Ann Neurol 44, S32-S44.

[47] Crichton RR, Ward RJ (2006) Metal-based Neurodegeneration: From Molecular Mechanisms to Therapeutic Strategies, John Wiley \& Sons, Ltd, Chichester, UK.

[48] Gruenheid S, Canonne-Hergaux F, Gauthier S, Hackam DJ, Grinstein S, Gros P (1999) The iron transport protein NRAMP2 is an integral membrane glycoprotein that colocalizes with transferrin in recycling endosomes. J Exp Med 189, $831-841$.

[49] Jefferies WA, Brandon MR, Hunt SV, Williams AF, Gatter KC, Mason DY (1984) Transferrin receptor on endothelium of brain capillaries. Nature 312, 162-163.

[50] Oshiro S, Nakajima H, Markello T, Krasnewich D, Bernardini I, Gahl WA (1993) Redox, transferrin-independent, and 
receptor-mediated endocytosis iron uptake systems in cultured human fibroblasts. J Biol Chem 268, 21568-21591.

[51] Burdo JR, Antonetti DA, Wolpert EB, Connor JR (2003) Mechanisms and regulation of transferrin and iron transport in a model blood-brain barrier system. Neuroscience 121, 883-890.

[52] Dickson PW, Aldred AR, Marley PD, Guo-Fen T, Howlett GJ, Schreiber G (1985) High prealbumin and transferrin mRNA levels in the choroid plexus of rat brain. Biochem Biophys Res Commun 127, 890-895.

[53] Roskams AJ, Connor JR (1990) Aluminum access to the brain: A role for transferrin and its receptor. Proc Natl Acad Sci U S A 87, 9024-9027.

[54] Hevner RF, Wong-Riley MTT (1992) Entorhinal cortex of the human monkey and rat: Metabolic map as revealed by cytochrome oxidase. J Comp Neurol 326, 451-469.

[55] Quillichini P, Sirota A, Buzsáki G (2010) Intrinsic circuit organization and theta-gamma oscillation dynamics in the entorhinal cortex of the rat. J Neurosci 30, 11128-11142.

[56] Collins DR, Lang EJ, Paré D (1999) Spontaneous activity of the perirhinal cortex in behaving cats. Neuroscience $\mathbf{8 9}$, 1025-1039.

[57] Borowsky IW, Collins RC (1989) Metabolic anatomy of brain: A comparison of regional capillary density, glucose metabolism, and enzyme activities. J Comp Neurol 288, 401413.

[58] Hill JM, Ruff MR, Weber RJ, Perl CB (1985) Transferrin receptors in rat brain: Neuropeptide-like pattern and relationship to iron distribution. Proc Natl Acad Sci U S A 82, 4553-4557.

[59] Mash DC, Pablo J, Flynn DD, Efange SMN, Weiner WJ (1990) Characterization and distribution of transferrin receptors in the rat brain. J Neurochem 55, 1972-1979.

[60] Morris CM, Keith AB, Edwardson JA, Pullen RGL (1992) Uptake and distribution of iron and transferrin in the adult rat brain. J Neurochem 59, 300-306.

[61] Morris CM, Candy JM, Bloxham CA, Edwardson JA (1982) Distribution of transferrin receptors in relation to cytochrome oxidase activity in the human spinal cord, lower brainstem and cerebellum. J Neurol Sci 111, 158-172.

[62] Crichton RR (2008) Biological Inorganic Chemistry: An Introduction. Elsevier, Amsterdam.

[63] Crichton RR, Dexter DT, Ward RJ (2011) Brain iron metabolism and its perturbation in neurological diseases. J Neural Transm 118, 301-314.

[64] Iwai K, Drake SK, Wehr NB, Weissman AM, LaVaute T, Minato N, Klausner RD, Levine RL, Rouault TA (1998) Iron-dependent oxidation, ubiquination, and degradation of iron regulatory protein 2: Implications for degradation of oxidized proteins. Proc Natl Acad Sci U S A 95, 4924-4928.

[65] Smith MA, Wehr K, Harris PL, Siedlak SL, Connor JR, Perry $\mathrm{G}$ (1998) Abnormal localization of iron regulatory protein in Alzheimer's disease. Brain Res 788, 232-236.

[66] Deibel MA, Ehmann WD, Markesbery WR (1996) Copper, iron, and zinc imbalances in severely degenerated brain regions in Alzheimer's disease: Possible relation to oxidative stress. J Neurol Sci 143, 137-142.

[67] Yamamoto A, Shin RW, Hasegawa K, Naiki H, Sato H, Yoshimasu F, Kitamoto T (2002) Iron (III) induces aggregation of hyperphosphorylated $\tau$ and its reduction to iron (II) reverses the aggregation: Implications in the formation of neurofibrillary tangles of Alzheimer's disease. J Neurochem 82, 1137-1147.

[68] Braak H, Braak E (1996) Development of Alzheimerrelated neurofibrillary changes in the neocortex inversely recapitulates cortical myelogenesis. Acta Neuropathol 92, 197-201.

[69] Braak H, Del Tredici K (2004) Poor and protracted myelination as a contributory factor to neurodegenerative disorders. Neurobiol Aging 25, 19-23.

[70] Kapphammer JP, Schwab ME (1994) Inverse patterns of myelination and GAP-43 expression in the adult CNS: Neurite growth inhibitors as regulators of neuronal plasticity. J Comp Neurol 340, 194-206.

[71] Nieuwenhuys R (1999) Structure and organisation of fibre systems. In The Central Nervous System of Vertebrates. Vol. 1. Nieuwenhuys R, Ten Donkelaar HJ, Nicholson C, eds. Springer Verlag, Berlin, pp. 113-157.

[72] Chaigneau E, Oheim M, Audinat E, Charpak S (2003) Twophoton imaging of capillary blood flow in olfactory bulb glomeruli. Proc Natl Acad Sci U S A 100, 13081-13088.

[73] Librizzi L, Biella G, Cimino C, De Curtis M (1999) Arterial supply of limbic structures in the guinea pig. J Comp Neurol 411, 674-682.

[74] Ashton D, Van Reempts J, Haseldoncksx M, Willems R (1989) Dorso-ventral gradient in vulnerability of CA1 hippocampus in ischemia: A combined histochemical and electrophysiological study. Brain Res 487, 368-372.

[75] Salamon G, Huang YP (1976) Radiologic Anatomy of the Brain. Springer Press, New York, pp. 332-344.

[76] Burdo JR, Simpson IA, Menzies S, Beard J, Connor JR (2003) Regulation of the profile of iron-management proteins in brain microvasculature. J Cereb Blood Flow Metab 24, 67-74.

[77] Gómez-Isla T, Price JL, McKeel DW Jr, Morris JC, Growdon JH, Hyman BT (1996) Profound loss of layer II entorhinal cortex neurons occurs in very mild Alzheimer's disease. J Neurosci 16, 4491-4500.

[78] Lee H, Rosenmann H, Chapman J, Kingsley PB, Hoffmann C, Cohen OS, Kahana E, Korczyn AD, Prohovnik I (2009) Thalamo-striatal diffusion reductions precede disease onset in prion mutation carriers. Brain 132, 2680-2687.

[79] Budka H, Aguzzi A, Brown P, Brucher JM, Bugiani O, Gullotta F, Haltia M, Hauw HM, Ironside JW, Jellinger K, Kretzschmar A, Lantos PL, Masullo C, Schlote W, Tateishi J, Weller RO (1995) Neuropathological diagnostic criteria for Creutzfeldt-Jakob disease (CJD) and other human spongiform encephalopathies (prion diseases). Brain Pathol 5, 459-466.

[80] Goudsmit J, Morrow CH, Asher DM, Yanagihara RT, Masters CL, Gibbs CJ Jr, Gajdusek DC (1980) Evidence for and against the transmissibility of Alzheimer disease. Neurology 30, 945-950.

[81] Brown P, Gibbs CJ Jr, Rodgers-Johnson P, Asher DM, Sulima MP, Bacore A, Goldfarb LG, Gajdusek DC (1994) Human spongiform encephalopathy: The National Institutes of Health Series of 300 cases of experimentally transmitted disease. Ann Neurol 35, 513-529.

[82] Teresa Sciortino M, Medici MA, Marino-Merlo F, Zaccaria D, Giuffre M, Venuti A, Grelli S, Mastino A (2007) Signaling pathway used by HSV-1 to induce NF-kappaB activation: Possible role of herpes virus entry receptor A. Ann NY Acad Sci 1096, 89-96.

[83] Lukiw WJ, Percy ME, Kruck TP (2005) Nanomolar aluminum induces pro-inflammatory and pro-apoptotic gene expression in human brain cells in primary culture. J Inorg Biochem 99, 1895-1898.

[84] Itzhaki RF, Wozniak MA (2010) Alzheimer's disease and infection: Do infectious agents contribute to progression of Alzheimer's disease? Alzheimers Dement 6, 83-84. 
[85] Esiri MM (1982) Viruses and Alzheimers disease. J Neural Neurosurg Psychiatr 45, 759.

[86] Mann DMA, Tinkler AM, Yates PO (1983) Neurological disease and herpes simplex virus. An immunohistochemical study. Acta Neuropathol (Berl) 60, 24-28.

[87] Wozniak MA, Mee AP, Itzhaki RF (2009) Herpes simplex virus type 1 DNA is located within Alzheimer's disease amyloid plaques. J Pathol 217, 131-138.

[88] Sequiera LW, Jennings LC, Carrasco LH, Lord MA, Curry A, Sutton RN (1979) Detection of Herpes simplex viral genome in brain tissue. Lancet 2, 609-612.

[89] Middleton PJP, Petric M, Kozak M, Rewcastle NB, McLachlan DR (1980) Herpes simplex viral genome and senile and presenile dementias of Alzheimer and Pick. Lancet 1, 1038.

[90] Taylor GR, Crow TJ, Markakis DA, Lofthouse R, Neeley S, Carter GI (1984) Herpes simplex and Alzheimers disease: A search for virus DNA by spot hybridisation. J Neurol Neurosurg Psychiatry 47, 1061-1065.

[91] Pogo BGT, Elizan TS (1985) Search for viral DNA sequences in Alzheimer brain tissue. Lancet i, 978-979.

[92] Whalley CJ, Urbaniak SJ, Darg C, Peutherer JF, Christie JE (1980) Histochompatiability antigens and antibodies to viral and other antigens in Alzheimers presenile dementia. Acta Psychiat Scand 61, 1-7.

[93] Renvoize EB, Awad IO, Hambling MH (1987) A seroepidemiological study of conventional infectious agents in Alzheimer's disease. Age Ageing 16, 311-314.

[94] Friedland RP, May C, Dahlberg J (1990) The viral hypothesis of Alzheimer's disease. Absence of antibodies to lentiviruses. Arch Neurol 47, 177-178.

[95] Ball MJ (1982) Limbic predilection in Alzheimer dementia: Is reactivated herpesvirus involved? Can J Neurol Sci $\mathbf{9}$, 303-306.

[96] Banatvala JE (2011) Herpes simplex encephalitis. Lancet 11, 80-81.

[97] Whitley RJ (2006) Herpes simplex encephalitis: Adolescents and adults. Antiviral Res 71, 141-148.

[98] Roberts GW, Taylor GR, Carter GI, Johnson JA, Bloxham C, Brown R, Crow TJ (1986) Herpes simplex virus: A role in the aetiology of Alzheimers disease? J Neurol Neurosurg Psychiat 49, 216-219.

[99] Whitley RJ, Gnann JW (2002) Viral encephalitis: Familiar infections and emerging pathogens. Lancet 359, 507-513.

[100] Amieva H, Le Goff M, Millet X, Orgogozo JM, Pérès K, Barberger-Gateau P, Jacqmin-Gadda H, Dartigues JF (2008) Prodromal Alzheimer's disease: Successive emergence of the clinical symptoms. Ann Neurol 64, 492-498.

[101] Niklowitz WJ, Mandybur TI (1975) Neurofibrillary changes following childhood lead encephalopathy. J Neuropathol Exp Neurol 34, 445-455.

[102] Hock C, Drasch G, Golombowski S, Muller-Spahn F, Willershausen-Zonnchen, Schwarz P, Hock U, Growdon JH, Nitsch RM (1998) Increased blood mercury levels in patients with Alzheimer's disease. J Neural Transm 105, 49-68.

[103] Markesbery WR, Ehmann WD, Alauddin M, Hossain TIM (1984) Brain trace element concentrations in aging. Neurobiol Aging 5, 19-28.

[104] Rusina R, Matej R, Kasparova L, Kukal J, Urban P (2011) Higher aluminum concentrations in Alzheimer's disease after Box-Cox data transformation. Neurotox Res 20, 329333.

[105] Golub MS, Gershwin ME, Donald JM, Negri S, Keen CL (1987) Maternal and developmental toxicity of chronic aluminum exposure in mice. Fund Appl Toxicol 8, 346-357.
[106] Anane R, Bonini M, Creppy EE (1997) Transplacental passage of aluminum from pregnant mice to fetus organs after maternal transcutaneous exposure. Human Exp Toxicol 16 , 501-504.

[107] Gilbert-Barness E, Barness LA, Wolff J, Harding C (1998) Aluminium toxicity. Arch Pediatr Adolesc Med 152, 511512.

[108] Roider G, Drasch G, Graw M (2011) Death following accidental intravenous infusion of an aluminium irrigation solution. Toxichem Krimtech 78, 344-346.

[109] Shoskes DA, Radzinski CA, Struthers NW, Honey RJ (1992) Aluminum toxicity and death following intravesical alum irrigation in a patient with renal impairment. J Urol 147, 697-699.

[110] Parkinson IS, Ward MK, Kerr DNS (1981) Dialysis encephalopathy, bone disease and anaemia: The aluminium intoxication syndrome during regular haemodialysis. J Clin Pathol 34, 1285-1294.

[111] Dunea G, Mahurkar SD, Mamdami B, Smith EC (1978) Role of aluminum in dialysis dementia. Ann lnt Med 88, 502-504.

[112] Arieff AI (1985) Aluminum and the pathogenesis of dialysis encephalopathy. Am J Kidney Dis 6, 317-321.

[113] Ackrill P, Day JP (1993) The use of desferrioxamine in dialysis-associated aluminium disease. Contrib Nephrol 102, 125-134.

[114] Harrington CR, Wischik CM, McArthur FK, Taylor GA, Edwardson JM, Candy JA (1994) Alzheimer's disease-like changes in tau protein processing: Association with aluminium accumulation in brains of renal diaysis patients. Lancet 343, 993-997.

[115] Shin RW, Iwaki T, Kitamoto T, Sato Y, Tateishi J (1992) Massive accumulation of modified tau and severe depletion of normal tau characterize the cerebral cortex and white matter of Alzheimer's disease. Demonstration using the hydrated autoclaving method. Am J Pathol 140, 937-945.

[116] De Boni U, Otvos A, Scott JW, Crapper DR (1976) Neurofibrillary degeneration induced by systemic aluminum. Acta Neuropathol 35, 285-294.

[117] Savory J, Ghribi O, Forbes MS, Herman MM (2001) The rabbit model system for studies of aluminum-induced neurofibrillary degeneration: Relevance to human neurodegenerative disorders. In Aluminium and Alzheimer's Disease. Exley C, ed. Elsevier Science, New York, pp. 203-219.

[118] Crapper DR (1976) Functional consequences of neurofibrillary degeneration. In Neurobiology of Aging. Terry RD, Gershon S, eds. Raven Press, New York, pp. 405-432.

[119] World Health Organization (1987) Aluminium. In 657. Aluminium WHO food additive series 24; 1989 [online]; http//www.inchem.org/documents/jecfa/jecmono/v024je07. htm [accessed September 23, 2012].

[120] Whitehead MW, Farrar G, Christie GL, Blair JA, Thompson RPH, Powell JJ (1997) Mechanisms of aluminum absorption in rats. Am J Clin Nutr 65, 1446-1452.

[121] Powell JJ, Ainley CC, Evans R, Thompson RPH (1994) Intestinal perfusion of dietary levels of aluminium: Association with the mucosa. Gut 35, 1053-1057.

[122] Walton J, Tuniz C, Fink D, Jacobsen G, Wilcox D (1995) Uptake of trace amounts of aluminum into the brain from drinking water. Neurotoxicology 16, 187-190.

[123] Drüeke TB, Jouhanneau P, Banide H, Lacour B (1997) Effects of silicon, citrate and the fasting state on the intestinal absorption of aluminium in rats. Clin Sci 92, 63-67.

[124] Zafar TA, Weaver CM, Martin BR, Flarend R, Elmore D (1997) Aluminum 26Al metabolism in rats. Proc Soc Exp Biol Med 216, 81-85. 
[125] Anane R, Bonini M, Grafeille JM, Creppy EE (1995) Bioaccumulation of water soluble aluminium chloride in the hippocampus after transdermal uptake in mice. Arch Toxicol 69, 568-571.

[126] Nicholson S, Exley C (2007) Aluminum: A potential prooxidant in sunscreens/sunblocks? Free Rad Biol Med 43, 1216-1217.

[127] Flarend RE, Hem SL, White JL, Elmore D, Suckow MA, Rudy AC, Dandashli EA (1997) In vivo absorption of aluminium-containing vaccine adjuvants using 26Al. Vaccine 15, 1314-1318.

[128] Tomljenovic L (2011) Aluminum and Alzheimer's disease: After a century of controversy, is there a plausible link? J Alzheimers Dis 23, 567-598.

[129] Redhead K, Quinlan GJ, Das RG, Gutteridge JMC (1992) Aluminium-adjuvanted vaccines transiently increase aluminium levels in murine brain tissue. Pharmacol Toxicol 70, 278-280.

[130] Lione A (1985) Aluminum toxicology and the aluminumcontaining medications. Pharmacol Ther 29, 255-285.

[131] Kavoussi LR, Gelstein LD, Andriole GL (1986) Encephalopathy and an elevated serum aluminum level in a patient receiving intravesical alum irrigation for severe urinary hemorrhage. J Urol 136, 665-667.

[132] Hantson P, Mahieu P, Gersdorff M, Sindic C, Lauwerys R (1995) Fatal encephalopathy after otoneurosurgery procedure with an aluminum-containing biomaterial. $J$ Toxicol Clin Toxicol 33, 645-648.

[133] Greger JL (1993) Aluminum metabolism. Annu Rev Nutr 13, 42-63.

[134] Walton JR (2012) Evidence that total dietary aluminum ingestion is a major risk factor for Alzheimer's disease. Curr Inorg Chem 2, 19-39.

[135] Crapper DR, Krishnan SS, Dalton AJ (1973) Brain aluminum distribution in Alzheimer's disease and experimental neurofibrillary degeneration. Science $\mathbf{1 8 0}$ 511-513.

[136] McDermott JR, Smith AI, Iqbal K, Wisniewski HM (1979) Brain aluminum in aging and Alzheimer disease. Neurology 29, 809-814.

[137] Markesbery WR, Ehmann WD, Hossain TI, Alauddin M, Goodin DT (1981) Instrumental neutron activation analysis of brain aluminum in Alzheimer disease and aging. Ann Neurol 10, 511-516.

[138] Shimizu H, Mori T, Koama M, Sekiya M, Ooami H (1994) A correlative study of the aluminum content and aging changes of the brain in non-demented elderly subjects. Nihon Ronen Igakkai Zasshi 31, 950-960.

[139] World Health Organization (2007) Evaluation of certain food additives and contaminants. In: Sixty-seventh report of the joint FAO/WHO Expert Committee on Food Additives, WHO Technical Report Series 940. http://www.who.int/ ipcs/publications/jecfa/reports/trs940.pdf [accessed, September 12, 2012].

[140] Walton JR (2006) Aluminum accumulation in hippocampal neurons from Alzheimer cases and aged controls. Neurotoxicology 27, 385-394.

[141] De Boni U, Scott JW, Crapper DR (1974) Intracellular aluminium binding: A histochemical study. Histochemistry $\mathbf{4 0}$, 31-37.

[142] Walton JR (2004) A bright field/fluorescent stain for aluminum: Its specificity, validation, and staining characteristics. Biotech Histochem 79, 169-176.

[143] Walton JR (2009) Brain lesions comprised of aluminumrich cells that lack microtubules may be associated with the cognitive deficit of Alzheimer's disease. Neurotoxicology 30, 1059-1069.

[144] Levy R, Shohat L, Solomon B (1998) Specificity of an antialuminium monoclonal antibody toward free and proteinbound aluminium. J Inorg Biochem 69, 159-163.

[145] Solomon B, Koppel R, Jossiphov J (2001) Immunostaining of calmodulin and aluminium in Alzheimer's diseaseaffected brains. Brain Res Bull 55, 253-256.

[146] Walton JR (2009) Functional impairment in aged rats chronically exposed to human range dietary aluminum equivalents. Neurotoxicology 30, 182-293.

[147] Loesche J, Steward O (1977) Behavioral correlates of denervation and reinnervation of the hippocampal formation of the rat: Recovery of alternation performance following unilateral entorhinal cortex lesions. Brain Res Bull 2, 31-39.

[148] Everitt AV (1991) Ageing rat colonies at the University of Sydney. Proc Aust Assoc Gerontol 26, 79-82.

[149] Walton JR (2013) Cognitive deterioration and related neuropathology in older people with Alzheimer's disease could result from life-long exposure to aluminium compounds. In Aging and Vulnerability to Environmental Chemicals: Age-related Disorders and their origins in Environmental Exposures. Weiss B, ed. RSC Publishing, London, pp. 26-77.

[150] Kowall NW, Pendlebury WW, Kessler JB, Perl DP, Beal MF (1989) Aluminum-induced neurofibrillary degeneration affects a subset of neurons in rabbit cerebral cortex, basal forebrain and upper brainstem. Neuroscience 29, 329-337.

[151] Edwardson JA, Ferrier I, McArthur FK, McKeith IG, McLaughlin I, Morris CM, Mountfort SA, Oakley AE, Taylor GA, Ward MK, Candy JM (1991) Alzheimer's disease and the aluminium hypothesis. In Aluminum in Chemistry Biology and Medicine. A Series of Advances. Nicolini M, Zatta PF, Corain B, eds. vol. 1, Raven Press, New York, pp. 85-96.

[152] Moore PB, Day JP, Taylor GA, Ferrier IN, Fifield LK, Edwardson JA (2000) Absorption of aluminium-26 in Alzheimer's disease, measured using accelerator mass spectrometry. Dement Geriatr Cogn Disord 11, 66-69.

[153] Kellet JM, Taylor A, Oram JJ (1986) Aluminosilicates and Alzheimer's disease. Lancet i, 682.

[154] Naylor GJ, Smith AHW, McHarg A, Walker P, Shepherd B, Ward NI, Harper M (1989) Raised serum aluminum concentrations in Alzheimer's disease. Trace Elem Psychiatry 6, 93-95.

[155] Van Rhijn A, Corrigan FM, Ward NI (1989) Serum aluminum in senile dementia of Alzheimer's type and in multi-infarct dementia. Trace Elem Med 6, 24-26.

[156] Corrigan FM, Crichton JS, Van Rhijn AG, Skinner ER, Ward NI (1992) Transferrin, cholesterol and aluminum in Alzheimer's disease. Clin Chim Acta 211, 121-123.

[157] Zapatero MD, Garcia de Jalon A, Pascual F, Calvo ML, Escanero J, Marro A (1995) Serum aluminum levels in Alzheimer's disease and other senile dementias. Biol Trace Elem Res 47, 235-240.

[158] Roberts NB, Clough A, Bellia JP, Kim JY (1998) Increased absorption of aluminium from a normal dietary intake in dementia. J Inorg Biochem 69, 171-176.

[159] Smorgon C, Mari E, Atti AR, Dalla Nora E, Zamboni PF, Calzoni F, Passaro A, Fellin R (2004) Trace elements and cognitive impairment: An elderly cohort study. Arch Gerontol Geriatr Suppl 9, 393-402.

[160] Moore PB, Edwardson JA, Ferrier IN, Taylor GA, Lett D, Tyrer SP, Day JP, King SJ, Lilley JS (1997) Gastrointestinal absorption of aluminum is increased in Down's syndrome. Biol Psychiatry 41, 488-492. 
[161] Puig KL, Swigost AJ, Zhou X, Sens MA, Combs CK (2012) Amyloid precursor protein expression modulates intestine immune phenotype. J Neuroimmune Pharmacol 7, 215-230.

[162] Galloway S, Pallebage-Gamarallage MMS, Takechi R, Jian L, Johnsen RD, Dhaliwal SS, Mamo JC (2008) Synergistic effects of high fat feeding and apolipoprotein E deletion on enterocytic amyloid-beta abundance. Lipids Health Dis 7, 15 .

[163] Walton JR, Wang M-X (2009) APP expression, distribution and accumulation are altered by aluminum in a rodent model for Alzheimer's disease. J Inorg Biochem 103, 1548-1554.

[164] Trapp GA (1978) Aluminum levels in brain in Alzheimer's disease. Biol Psychiatry 13, 709-718.

[165] Yoshimasu F, Yasui M, Yoshida H, Yoshida S, Labayashi Y, Yase Y, Gadjusek DC, Chen K (1985) Aluminum in Alzheimer's disease in Japan and Parkinsonism-dementia in Guam. XII World Congress of Neurology, Hamburg, Abstract 15-07-02.

[166] Xu N, Majidi V, Markesbery WR, Ehmann WD (1992) Brain aluminum in Alzheimer's disease using an improved GFAAS method. Neurotoxicology 13, 735-743.

[167] Corrigan FM, Reynolds GP, Ward NI (1993) Hippocampal tin, aluminum and zinc in Alzheimer's disease. Biometals 6 , 149-154.

[168] Andrási E, Páli N, Molnár Z, Kösel S (2005) Brain Al, Mg and $\mathrm{P}$ contents of control and Alzheimer-diseased patients. J Alzheimers Dis 7, 273-284.

[169] Perl DP, Brody AR (1980) Alzheimer's disease: X-ray spectrometric evidence of aluminum accumulation in neurofibrillary tangle-bearing neurons. Science 208, 297-299.

[170] Good PF, Perl DP, Bierer LM, Schmeidler J (1992) Selective accumulation of aluminum and iron in the neurofibrillary tangles of Alzheimer's disease: A laser microprobe LAMMA study. Ann Neurol 31, 286-292.

[171] Ganrot PO (1986) Metabolism and possible health effects of aluminium. Environ Health Persp 65, 363-441.

[172] Crapper McLachlan DR (1986) Aluminum and Alzheimer's disease. Neurobiol Aging 7, 525-532.

[173] Crapper DR, Tomko GJ (1975) Neuronal correlates of an encephalopathy associated with aluminum neurofibrillary degeneration. Brain Res 97, 253-264.

[174] Oddo S, Caccamo A, Shepherd JD, Murphy MP, Golde TE, Kayed R, Metherate R, Mattson MP, Akbari Y, LaFerla FM (2003) Triple-transgenic model of Alzheimer's disease with plaques and tangles: Intracellular Abeta and synaptic dysfunction. Neuron 39, 409-421.

[175] Drago D, Cavaliere A, Mascetra N, Ciavardelli D, de Ilio C, Zatta P, Sensi SL (2008) Aluminum modulates effects of ßamyloid $_{1-42}$ on neuronal calcium homeostasis and mitochondria functioning and is altered in a triple transgenic mouse model of Alzheimer's disease. Rejuv Res 11, 861871.

[176] Mann DM, Esiri MM (1989) The pattern of acquisition of plaques and tangles in the brains of patients under 50 years of age with Down's syndrome. J Neurol Sci 89, 169-179.

[177] Wisniewski KE, Dalton AJ, Crapper McLachlan DR, Wen GY, Wisniewski HM (1985) Alzheimer's disease in Down's syndrome. Neurology 35, 957-961.

[178] Martin RB (1986) The chemistry of aluminum as related to biology and medicine. Clin Chem 32, 1797-1806.

[179] Cowan JA (2002) Structural and catalytic chemistry of magnesium-dependent enzymes. Biometals 15, 225-235.

[180] Macdonald TL, Humphreys WG, Martin RB (1987) Promotion of tubulin assembly by aluminum ion in vitro. Science 236, 183-186.
[181] Walton JR (2012) Aluminum disruption of calcium homeostasis and signal transduction resembles change that occurs in aging and Alzheimer's disease. J Alzheimers Dis 29, 255 273.

[182] Trapp GA (1986) Interactions of aluminium with cofactors, enzymes and other proteins. Kidney Int 29, S12-S16.

[183] Yamanaka K, Minato N, Iwai K (1999) Stabilization of iron regulatory protein 2, IRP2, by aluminum. FEBS Lett $\mathbf{4 6 2}$, 216-220.

[184] Platt B, Busselberg D (1994) Actions of aluminum on voltage-activated calcium channel currents. Cell Mol Neurobiol 13, 819-829.

[185] Platt B, Haas H, Busselberg D (1994) Aluminium reduces glutamate-activated currents of rat hippocampal neurones. Neuroreport 5, 2329-2332.

[186] Busselberg D (1995) Calcium channels as target sites of heavy metals. Toxicol Lett 82, 255-261.

[187] Exley C (2004) The pro-oxidant activity of aluminum. Free Rad Biol Med 36, 380-387.

[188] Becaria A, Lahiri DK, Bondy SC, Chen D, Hamadeh A, Li H, Taylor R, Campbell A (2006) Aluminum and copper in drinking water enhance inflammatory or oxidative events specifically in the brain. J Neuroimmunol 176, 16-23.

[189] Garcia T, Esparza JL, Nogues MR, Domingo JL, Gomez M (2010) Oxidative stress status and RNA expression in hippocampus of an animal model of Alzheimer's disease after chronic exposure to aluminum. Hippocampus 20, 218225.

[190] Flendrig JA, Kruis H, Das HA (1976) Aluminium and dialysis dementia. Lancet 1, 1235.

[191] Alfrey AC, LeGendre GR, Kaehny WD (1976) The dialysis encephalopathy syndrome, possible aluminium intoxication. N Engl J Med 294, 184-188.

[192] Kobayashi S, Hirota N, Saito K, Utsuyama M (1987) Aluminum accumulation in tangle-bearing neurons of Alzheimer's disease with Balint's syndrome in a long-term aluminum refiner. Acta Neuropathol 74, 47-52.

[193] Garruto RM, Swyt C, Yanagihara R, Fiori CE, Gajdusek DC (1986) Intraneuronal co-localization of silicon with calcium and aluminum in amyotrophic lateral sclerosis and parkinsonism with dementia of Guam. New Engl J Med 315 , 711-712.

[194] Garruto RM, Brown P (1994) Tau protein, aluminium and Alzheimer's disease. Lancet 343, 989.

[195] Yasui M, Kihira T, Ota K (1992) Calcium, magnesium and aluminum concentrations in Parkinson's disease. Neurotoxicology 13, 593-600.

[196] Rifat SL, Eastwood MR, McLachlan DR, Corey PN (1990) Effect of exposure of miners to aluminium powder. Lancet 336, 1162-1165.

[197] Gong C-X, Lidsky T, Wegiel J, Zuck L, Grundke-Iqbal I (2000) Phosphorylation of microtubule-associated protein tau is regulated by protein phosphatase $2 \mathrm{~A}$ in mammalian brain. Implications for neurofibrillary degeneration in Alzheimer's disease. J Biol Chem 275, 5535-5544.

[198] Vogelsberg-Ragaglia V, Schuck T, Trojanowski JQ, Lee VM-Y (2001) PP2A mRNA expression is quantitatively decreased in Alzheimer's disease hippocampus. Exp Neurol 168, 402-412.

[199] Bancher C, Brunner C, Lassmann H, Budka H, Jellinger $\mathrm{K}$, Wiche G, Seitelberger F, Grundke-Iqbal I, Iqbal K, Wisniewski HM (1989) Accumulation of abnormally phosphorylated $\tau$ precedes the formation of neurofibrillary tangles in Alzheimer's disease. Brain Res 477, 90-99. 
[200] Cork LC, Sternberger NH, Sternberger LA, Casanova MF, Struble RG, Price DL (1986) Phosphorylated neurofilament antigens in neurofibrillary tangles in Alzheimer's disease. J Neuropathol Exp Neurol 45, 56-64.

[201] Perry G, Rizzuto N, Autilio-Gambetti L, Gambetti P (1985) Paired helical filaments from Alzheimer disease patients contain cytoskeletal components. Proc Natl Acad Sci U S A 82, 3915-3920.

[202] Vickers JC, Morrison JH, Friedrich VL Jr, Elder GA, Perl DP, Katz RN, Lazzarini RA (1994) Age-associated and cell-type-specific neurofibrillary pathology in transgenic mice expressing the human midsized neurofilament subunit. J Neurosci 14, 5603-5612.

[203] Sternberger NH, Sternberger LA, Ulrich J (1985) Aberrant neurofilament phosphorylation in Alzheimer disease. Proc Natl Acad Sci U S A 82, 4274-4276.

[204] Gong CX, Wang JZ, Iqbal K, Grundke-Iqbal I (2003) Inhibition of protein phosphatase $2 \mathrm{~A}$ induces phosphorylation and accumulation of neurofilaments in metabolically active rat brain slices. Neurosci Lett 340, 107-110.

[205] Rudrabhatla P, Grant P, Jaffe H, Strong MJ, Pant HC (2010) Quantitative phosphoproteomic analysis of neuronal intermediate filament proteins (NF-M/H) in Alzheimer's disease by ITRAQ. FASEB J 24, 4396-4407.

[206] Wang J, Tung YC, Wang Y, Li XT, Iqbal K, Grundke-Iqbal I (2001) Hyperphosphorylation and accumulation of neurofilament proteins in Alzheimer disease brain and in okadaic acid-treated SY5Y cells. FEBS Lett 507, 81-87.

[207] Kins S, Crameri A, Evans DR, Hemmings BA, Nitsch RM, Gotz J (2001) Reduced protein phosphatase 2A activity induces hyperphosphorylation and altered compartmentation of tau in transgenic mice. $J$ Biol Chem 276, 38193-38200.

[208] Ksiezak-Reding H, Dickson DW, Davies P, Yen S-H (1987) Recognition of tau epitopes by anti-neurofilament antibodies that bind to Alzheimer neurofibrillary tangles. Proc Natl Acad Sci U S A 84, 3410-3414.

[209] Liang Z, Liu F, Iqbal K, Grundke-Iqbal I, Wegiel J, Gong CX (2008) Decrease of protein phosphatase 2A and its association with accumulation and hyperphosphorylation of tau in Down syndrome. J Alzheimers Dis 13, 303-321.

[210] Talja I, Reimand T, Uibo O, Reimand K, Aun S, Talvik T, Janmey PA, Uibo R (2009) Antibodies to neurofilaments. Clinical and immunogenetic associations in Down syndrome. Ann NY Acad Sci 1173, 130-136.

[211] Yamamoto H, Saitoh Y, Yasugawa S, Miyamoto E (1990) Dephosphorylation of tau factor by protein phosphatase $2 \mathrm{~A}$ in synaptosomal cytosol fractions, and inhibition by aluminum. J Neurochem 55, 683-690.

[212] Walton JR (2007) An aluminum-based rat model for Alzheimer's disease exhibits oxidative damage, inhibition of PP2A activity, hyperphosphorylated tau, and granulovacuolar degeneration. J Inorg Biochem 101, 1275-1284.

[213] Guy SP, James D, Mann DMA, Itzhaki RF (1991) Human neuroblastoma cells treated with aluminum express an epitope associated with Alzheimer's disease neurofibrillary tangles. Neurosci Lett 121, 166-168.

[214] Abdel-Ghany M, El-Sabae AKK, Shalloway D (1993) Aluminum-induced non-enzymatic phospho-incorporation into human tau and other proteins. J Biol Chem 168, 1197611981.

[215] Savory J, Huang Y, Herman MM, Reyes MR, Wills MR (1995) Tau immunoreactivity associated with aluminum maltolate-induced neurofibrillary degeneration in rabbits. Brain Res 669, 325-329.
[216] Savory J, Huang Y, Herman MM, Wills MR (1996) Quantitative image analysis of temporal changes in tau and neurofilament proteins during the course of acute experimental neurofibrillary degeneration, non-phosphorylated epitopes precede phosphorylation. Brain Res 707, 272-281.

[217] Murayama H, Shin R-W, Higuchi J, Shibuya S, Muramoto T, Kitamoto T (1999) Interaction of aluminum with PHFtau in Alzheimer's disease neurofibrillary degeneration evidenced by desferrioxamine-assisted chelating autoclave method. Am J Pathol 155, 877-882.

[218] Shin R-W (1997) Interaction of aluminum with paired helical filament tau is involved in neurofibrillary pathology of Alzheimer's disease. Gerontology 43(Suppl), 16-23.

[219] Huang Y, Herman MM, Liu J, Katsetos CD, Wills MR, Savory J (1997) Neurofibrillary lesions in experimental aluminum-induced encephalopathy and Alzheimer's disease share immunoreactivitiy for amyloid precursor protein, $A \beta, \alpha 1$-antichymotrypsin and ubiquitin-protein conjugates. Brain Res 771, 213-220.

[220] Götz J (2001) Tau and transgenic animal models. Brain Res Rev 35, 266-286.

[221] de Calignon A, Fox LM, Pitstick R, Carlson GA, Bacskai BJ, Spires-Jones TL, Hyman BT (2010) Caspase activation precedes and leads to tangles. Nature 464, 1201-1203.

[222] Yang S-J, Lee JE, Lee KW, Huh J-W, Choi SY, Cho S-W (2004) Opposed regulation of aluminum-induced apoptosis by glial cell line-derived neurotrophic factor and brainderived neurotrophic factor in rat brains. Mol Brain Res 127, 146-149.

[223] Ghribi O, Herman MM, Savory J (2002) The endoplasmic reticulum is the main site for caspase-3 activation following aluminum-induced neurotoxicity in the hippocampus. Neurosci Lett 324, 217-221.

[224] Guillozet-Bongaarts AL, Garcia-Sierra F, Reynolds MR, Horowitz PM, Fu Y, Wang T, Cahill ME, Bigio EH, Berry RW, Binder LI (2005) Tau truncation during neurofibrillary tangle evolution in Alzheimer's disease. Neurobiol Aging 26, $1015-1022$.

[225] Walton JR (2010) Evidence for participation of aluminum in neurofibrillary tangle formation and growth in Alzheimer's disease. J Alzheimers Dis 22, 65-72.

[226] Uemura E (1984) Intranuclear aluminium accumulation in chronic animals with experimental neurofibrillary changes. Exp Neurol 85, 10-18.

[227] Hyman BT, Van Hoesen GW, Damasio AR, Barnes CL (1984) Alzheimer's disease: Cell-specific pathology isolates the hippocampal formation. Science 225, 1168-1170.

[228] Pratico D, Uryu K, Sung S, Tang S, Trojanowski JW, Lee VM-Y (2002) Aluminum modulates brain amyloidosis through oxidative stress in APP transgenic mice. FASEB $J$ 16, 1138-1141.

[229] Hatanpää K, Brady DR, Stoll J, Rapoport SI, Chandrasekaran K (1996) Neuronal activity and early neurofibrillary tangles in Alzheimer's disease. Ann Neurol 40, 411-420.

[230] Jovanović MD, Ninković M, Malicević Z, Mihajlović R, Micić D, Vasiljević I, Selaković V, Dukić M, Jovicić A (2000) Cytochrome C oxidase activity and total glutathione content in experimental model of intracerebral aluminium overload. Vojnosanit Pregl 57, 265-270.

[231] Bosetti F, Solaini G, Tendi EA, Chikhale EG, Chandrasekaran K, Rapoport SI (2001) Mitochondrial cytochrome c oxidase subunit III is selectively downregulated by aluminium exposure in $\mathrm{PC} 12 \mathrm{~S}$ cells. Neuroreport 12, 721-724. 
[232] Morsch R, Simon W, Coleman PD (1999) Neurons may live for decades with neurofibrillary tangles. J Neuropathol Exp Neurol 58, 188-197.

[233] Gray EG, Paula-Barbosa M, Roher A (1987) Alzheimer's disease: Paired helical filaments and cytomembranes. $\mathrm{Neu}$ ropathol Appl Neurobiol 13, 91-110.

[234] Hempen B, Brion J-P (1996) Reduction of acetylated $\alpha$-tubulin immunoreactivities in neurofibrillary tanglebearing neurons in Alzheimer's disease. J Neuropathol Exp Neurol 55, 964-972.

[235] Shigematsu K, McGeer PL (1992) Accumulation of amyloid precursor protein in damaged neuronal processes and microglia following intracerebral administration of aluminium salts. Brain Res 593, 117-123.

[236] Petit TL, Biederman GB, McCullen PA (1980) Neurofibrillary degeneration, dendritic dying back, and learning-memory deficits after aluminum administration: Implications for brain aging. Exp Neurol 67, 152-162.

[237] Uemura E, Ireland WP (1985) Dendritic alterations in chronic animals with experimental neurofibrillary changes. Exp Neurol 89, 530-542.

[238] Uemura E, Ireland WP (1984) Synaptic density in chronic animals with experimental neurofibrillary changes. Exp Neurol 85, 1-9.

[239] Jing Y, Wang Z, Song Y (2004) Quantitative study of aluminum-induced changes in synaptic ultrastructure in rats. Synapse 52, 292-298.

[240] Buell SJ, Coleman PD (1981) Quantitative evidence for selective dendritic growth in normal human aging but not in senile dementia. Brain Res 214, 33-41.

[241] Scheibel ME, Lindsay RD, Tomiyasu U, Scheibel AB (1976) Progressive dendritic changes in the aging human limbic system. Exp Neurol 53, 420-430.

[242] Simchowicz T (1914) La maladie d'Alzheimer et son rapport avec la démence sénile. L'Encéphale, 218-231.

[243] Woodard JS (1962) Clinicopathologic significance of granulovacuolar degeneration in Alzheimer's disease. $J \mathrm{Neu}$ ropathol Exp Neurol 21, 85-91.

[244] Okamoto K, Hirai S, Iizuka T, Yanagisawa T, Watanabe M (1991) Reexamination of granulovacuolar degeneration. Acta Neuropathol 82, 340-345.

[245] Sun X, Liu Z, Zhang X, Zhang Z (1999) Effects of aluminum on the number of neurons granulovacuolar degeneration in rats [Chinese]. Wei Sheng Yan Jiu 28, 164-166.

[246] Hirano A, Kurland LT, Krooth RS, Lessell S (1961) Parkinsonism-dementia complex, an endemic disease on the island of Guam. I. Pathological features. Brain 84, 642661.

[247] Armstrong RA (1995) Is the clustering of $\beta$-amyloid A $\beta$ deposits in the frontal cortex of Alzheimer patients determined by blood vessels? Neurosci Lett 195, 121-124.

[248] Kawahara M, Muramoto K, Kobayashi K, Mori H, Kuroda Y (1994) Aluminum promotes the aggregation of Alzheimer's amyloid beta-protein in vitro. Biochem Biophys Res Commun 198, 531-535.

[249] Caporaso GL, Gandy SE, Buxbaum JD, Ramabhadran TV, Greengard P (1992) Protein phosphorylation regulates secretion of Alzheimer $\beta /$ A4 amyloid precursor protein. Proc Natl Acad Sci U S A 89, 3055-3059.

[250] Buxbaum JD, Koo EH, Greengard P (1993) Protein phosphorylation inhibits production of Alzheimer amyloid $\beta / A 4$ peptide. Proc Natl Acad Sci U S A 90, 9195-9198.

[251] Cochran M, Elliott DC, Brennan P, Chawtur V (1990) Inhibition of protein kinase $\mathrm{C}$ activation by low concentrations of aluminium. Clin Chim Acta 194, 167-172.
[252] Kawahara M, Kato M, Kuroda Y (2001) Effect of aluminum on the neurotoxicity of primary cultured neurons and on the aggregation of $\beta$-amyloid protein. Brain Res Bull 55, 211-217.

[253] Drago D, Bolognin S, Zatta P (2008) Role of metal ions in the $A \beta$ oligomerization in Alzheimer's disease and in other neurological disorders. Curr Alzheimer Res 5, 500-507.

[254] Exley C, Price NC, Kelly SM, Birchall JD (1993) An interaction of beta-amyloid with aluminium in vitro. FEBS Lett 324, 293-295.

[255] House E, Collingwood J, Khan A, Korchazkina O, Berthon G, Exley C (2004) Aluminium, iron, zinc and copper influence the in vitro formation of amyloid fibrils of Abeta42 in a manner which may have consequences for metal chelation therapy in Alzheimer's disease. J Alzheimers Dis 6, 291-301.

[256] Shivers BD, Hilbich C, Multhaup G, Salbaum M, Beyreuther K, Seeburg PH (1988) Alzheimer's disease amyloidogenic glycoprotein: Expression pattern in rat brain suggests a role in cell contact. EMBO J 7, 1365-1370.

[257] Rodella LF, Ricci F, Borsani E, Stacchiotti A, Foglio E, Favero G, Rezzani R, Mariani C, Bianchi R (2008) Aluminium exposure induces Alzheimer disease-like histopathological alterations in mouse brain. Histol Histopathol 23, 433-439.

[258] Exley C, Esiri MM (2006) Severe cerebral congophilic angiopathy coincident with increased brain aluminium in a resident of Camelford, Cornwall, UK. J Neurol Neurosurg Psychiat 27, 877-879.

[259] Yumoto S, Kakimi S, Ohsaki A, Ishikawa A (2009) Demonstration of aluminum in amyloid fibers in the cores of senile plaques in the brains of patients with Alzheimer's disease. J Inorg Biochem 103, 1579-1584.

[260] Landsberg JP, McDonald B, Watt F (1992) Absence of aluminium in neuritic plaque cores in Alzheimer's disease. Nature 360, 65-68.

[261] Landsberg JP, McDonald B, Watt F (1993) Microanalysis of senile plaques using nuclear microscopy. J Geriatr Psychiat Neurol 6, 97-104.

[262] Sato N, Hori O, Yamaguchi A, Lambert J-C, Chartier-Harlin M-C, Robinson PA, Delacourte A, Schmidt AM, Furuyama T, Imaizumi K, Tohyama M, Takagi T (1999) A novel presenilin-2 splice variant in human Alzheimer's disease brain tissue. J Neurochem 72, 2498-2505.

[263] Sato N, Imaizumi K, Manabe T, Taniguchi M, Hitomi J, Katayama T, Yoneda T, Morihara T, Yasuda Y, Takagi T, Kudo T, Tsuda T, Itoyama Y, Makifuchi T, Fraser PE, St George-Hyslop P, Tohyama M (2001) Increased production of $\beta$-amyloid and vulnerability to endoplasmic reticulum stress by an aberrant spliced form of presenilin 2. J Biol Chem 276, 2108-2113.

[264] Matsuzaki S, Manabe T, Katayama T, Nishikawa A, Yanagita T, Okuda H, Hasuda Y, Miyata S, Meshitsuka S, Tohyama M (2004) Metals accelerate production of the aberrant splicing isoform of the presenilin-2. J Neurochem $\mathbf{8 8}$, 1345-1351.

[265] Bondy SC (2010) The neurotoxicity of environmental aluminum is still an issue. Neurotoxicology 31, 575-581.

[266] Trapp GA (1983) Plasma aluminum is bound to transferrin. Life Sci 33, 311-316.

[267] Day JP, Barker J, Evans LJA, Perks J, Seabright PJ, Ackrill P, Lilley JS, Drumm PV, Newton GWA (1991) Aluminium absorption studied by ${ }^{26} \mathrm{Al}$ tracer. Lancet 337, 1345.

[268] Yokel RA (2006) Blood-brain barrier flux of aluminum, manganese, iron and other metals suspected to contribute 
to metal-induced neurodegeneration. J Alzheimers Dis $\mathbf{1 0}$, 223-253.

[269] Oshiro S, Kawahara M, Mika S, Muramoto K, Kobayashi K, Ishige R, Nozawa K, Hori M, Yung C, Kitajima S, Kuroda Y (1998) Aluminum taken up by transferrin-independent iron uptake affects the iron metabolism in rat cortical cells. J Biochem 123, 42-46.

[270] Abreo K, Abreo F, Sella M, Jain S (1999) Aluminum enhances iron uptake and expression of neurofibrillary tangle protein in neuroblastoma cells. J Neurochem 72, 2059-2064.

[271] Perez G, Garbossa G, Sassetti B, Di Risio C, Nesse A (1999) Interference of aluminium on iron metabolism in erythroleukaemia K562 cells. J Inorg Biochem $\mathbf{7 6}$ 105-112.

[272] Ward RM, Zhang Y, Crichton RR (2001) Aluminum toxicity and iron homeostasis. J Inorg Biochem 87, 9-14.

[273] Zecca L, Gallorinin M, Schunemann V, Trautwein AX, Gerlach M, Riederer P, Vezzoni P, Tampellini D (2001) Iron, neuromelanin and ferritin content in the substantia nigra of normal subjects at different ages: Consequences for iron storage and neurodegenerative processes. J Neurochem $\mathbf{7 6}$ 1766-1773.

[274] Kong S, Liochev S, Fridovich I (1992) Aluminum III facilitates the oxidation of NADPH by the superoxide anion. Free Rad Biol Med 13, 79-81.
[275] Bondy SC, Guo-Ross S, Pien J (1998) Mechanisms underlying the aluminum-induced potentiation of the pro-oxidant properties of transition metals. Neurotoxicology 19, 65-71.

[276] Yang EY, Guo-Ross SX, Bondy SC (1999) The stabilization of ferrous iron by a toxic $\beta$-amyloid fragment and by an aluminium salt. Brain Res 839, 221-226.

[277] Karlik SJ, Eichhorn GL (1989) Polynucleotide cross-linking by aluminum. J Inorg Biochem 37, 259-269.

[278] Crapper DR, Lukiw WJ, Kruck TPA (1990) Aluminum, altered transcription, and the pathogenesis of Alzheimer's disease. Environ Geochem Health 12, 103-114.

[279] Kalaria R (2002) Similarities between Alzheimer's disease and vascular dementia. J Neurol Sci 203-204, 29-34.

[280] Perl DP, Good PF (1987) Uptake of aluminium into central nervous system along nasal-olfactory pathways. Lancet $\mathbf{i}$, 1028 .

[281] Troncoso JC, Sternberger NH, Sternberger LA, Hoffman PN, Price DL (1986) Immunocytochemical studies of neurofilament antigens in the neurofibrillary pathology induced by aluminum. Brain Res 364, 295-300.

[282] Shea TB, Beermann ML, Nixon RA (1995) Aluminum treatment of intact neuroblastoma cells alters neurofilament subunit phosphorylation. Mol Chem Neuropathol 26, 1-14

[283] Shin RW, Lee VM, Trojanowski JQ (1994) Aluminum modifies the properties of Alzheimer's disease PHF tau proteins in vivo and in vitro. J Neurosci 14, 7221-7233. 